\title{
LA BANDERA Y LA CAPITALIDAD
}

ANTONIO TRONCOSO REIGADA 
SUMARIO

I. LOS SÍMBOLOS. II. LA BANDERA. 1. LA BANDERA COMO SÍMBOLO DEL ESTADO Y COMO ELEMENTO DE INTEGRACIÓN DE LOS CIUDADANOS EN LA COMUNIDAD Y LA CONSTITUCIONALIZACIÓN DE LAS BANDERAS AUTONÓMICAS. 2. LOS CONFLICTOS POR EL USO DE LAS BANDERAS: LA GUERRA DE LAS BANDERAS. A) LA OBLIGACIÓN DE UTILIZAR LA BANDERA DE ESPAÑA EN EDIFICIOS PÚBLICOS Y ACTOS OFICIALES Y SUS INCUMPLIMIENTOS. B) LA PROTECCIÓN PENAL DE LA BANDERA Y SU CUESTIONAMIENTO COMO LÍMITE A LA LIBERTAD DE EXPRESIÓN. C) LA PROHIBICIÓN DE LA EXHIBICIÓN EN EDIFICIOS PÚBLICOS DE BANDERAS PARTIDISTAS Y DE LA UTILIZACIÓN PARTIDISTA DE LA BANDERA DE ESPAÑA. D) LOS CONFLICTOS POR LA UTILIZACIÓN DE LAS BANDERAS DE LAS COMUNIDADES AUTÓNOMAS. III. LA CAPITALIDAD. 1. EL CONCEPTO CONSTITUCIONAL DE CAPITALIDAD: LA SEDE DE LAS INSTITUCIONES GENERALES DEL ESTADO. 2. MATERIAS OBJETO DEL RÉGIMEN DE CAPITALIDAD. LA SINGULARIDAD DE MADRID. 


\title{
LA BANDERA Y LA CAPITALIDAD
}

\author{
ANTONIO TRONCOSO REIGADA ${ }^{1}$ \\ Catedrático de Derecho Constitucional de la Universidad de Cádiz
}

\section{LOS SÍMBOLOS}

La bandera y la capitalidad son dos elementos que han estado presentes en la conformación de nuestra identidad nacional, un proceso que en nuestro país ha estado acompañado tradicionalmente por el debate, cuando no por el enfrentamiento, entre el centro y la periferia ${ }^{2}$. Sin embargo, menos énfasis se ha puesto en el papel que los símbolos han tenido en la relación entre persona, sociedad y Estado, un difícil equilibrio en los Estado democráticos esencial para alejarnos de los totalitarismos. La necesidad de simbolizar colectividades proviene de una tendencia progresiva del hombre hacia la socialización que está en contra de la individualidad plena. En Ortega u Gasset, este fenómeno se contempla de forma muy estimulante, que da que pensar: «la socialización del hombre es una faena pavorosa. Porque no se contenta con exigirme que lo mío sea para los demás - propósito excelente que no me causa enojo alguno-, sino que me obliga a que lo de los demás sea mío» ${ }^{3}$. Por ello, «cabe decir que la mitad de nuestro ser radica en lo que sean los demás» ${ }^{4}$. Los símbolos como la bandera despiertan corrientes colectivas, que lógicamente, plantean problemas en lo que se refiere a la conciencia individual. Es discutible que pueda hablarse propiamente de una «conciencia colectiva» que en el fondo no sería más que la suma de propiedades

${ }^{1}$ Catedrático de Derecho Constitucional de la Universidad de Cádiz. Departamento de Disciplinas Jurídicas Básicas. Facultad de Derecho. Campus de Jerez. Avda. de la Universidad n. ${ }^{\circ} 4$ — 11406- Jerez de la Frontera (Cádiz). Email: antonio.troncosoreigada@uca.es

${ }^{2}$ Cfr. ORTEGA Y GASSET, J., España invertebrada. Bosquejos de algunos pensamientos históricos, Madrid, Revista de occidente, 1951, pág. 22.

3 Cfr. ORTEGA Y GASSET, J., «Socialización del hombre», El Espectador, vol. VIII, Madrid, Revista de occidente, 1934.a, pág. 191.

${ }^{4}$ Cfr. ORTEGA Y GASSET, J., «Sobre el fascismo», El Espectador, vol. IV, V y VI, Madrid, Revista de occidente, 1936, pág. 327. 
y comportamientos de individuos ${ }^{5}$. Además, se ha discutido si el término conciencia es apropiado por cuanto «los procesos sociales colectivos son a menudo, inconscientes ${ }^{6}$. En esta dirección señalaba KANT que «constituye un contrasentido y una inexactitud el uso de la palabra «simbólico» como opuesta al modo de representación intuitivo, puesto que lo simbólico es sólo una especie de intuitivo» ${ }^{7}$. De alguna manera, lo simbólico se opone a lo racional, o, en palabras de Sperber, lo simbólico es lo mental menos lo racional ${ }^{8}$. En todo caso, lo simbólico es lo que Pareto denominaba un «residuo», los elementos constantes e irracionales que configuran lo eterno y esencia del hombre ${ }^{9}$. Por tanto, residuo y símbolo tienen un espacio en común. Bien lo saben los nacionalistas ${ }^{10}$, los fascistas y los populistas que siempre han hecho gala de una gran capacidad para manipular en este espacio ${ }^{11}$.

5 Para HABERMAS, «sería falso representar las identidades grupales como "identidades del yo" en gran formato; entre ambas no se da ninguna analogía, sino tan solo una relación de complementariedad». Cfr. HABERMAS, J., Identidades nacionales y posnacionales, Tecnos, Madrid, 1989, págs. 100-101.

${ }^{6}$ La expresión conciencia colectiva, propuesta y desarrollada por EMILE DURKHEIM, es un término sociológico, pero que tiene implicaciones psicológicas. Autores con propensiones nominalistas y los llamados «individualistas metodológicos» han rechazado el concepto de una conciencia colectiva. Cfr. FERRATER MORA, J., Diccionario de filosofía, vol. 1, Madrid, Alianza Editorial, 2001, pág. 135.

7 Cfr. KANT, I., Kant's Werke, Akademie Textausgabe, Berlin, Band V, 1908, págs. 351-352.

8 «Dos criterios han servido, alternativamente, para delimitar el campo del simbolismo. Según el primer criterio, lo simbólico es lo mental menos lo racional; conforme al segundo, es lo semiótico menos la lengua. En ambos casos es un residuo». Cfr. SPERBER, D., El símbolo en general, Barcelona, Editorial Anthropos, 1998. SMEND también subraya la vinculación entre el irracionalismo y el simbolismo, "cuya fundamentación histórica se halla en la falta de expresividad propia de tiempos más primitivos». Cfr. SMEND, R., Constitución y Derecho Constitucional, CEC, Madrid, 1985, págs. 97-98. También GARRORENA MORALES, A. ha subrayado que «el pensamiento simbólico pertenece al mundo del pensamiento mítico, intuitivo o pre-racional y, a su lado existe el pensamiento basado en la razón al que es necesario reservar siempre el alto lugar que le corresponde» — «Los símbolos de las comunidades autónomas y la función del Derecho», en AGUIAR DE LUQUE L. et al., Constitución, Estado de las autonomías y justicia constitucional, Libro bomenaje al profesor Gumersindo Trujillo, Tirant lo Blanch, Valencia, 2005, pág. 1016-.

9 PARETO se convirtió en senador fascista debido a la admiración que le profesaba Mussolini. PARETO intentó construir una ontología del hombre en la cual debían separarse realidad y apariencia para llegar a su esencia. La esencia era para él lo irracional. Las conductas racionales, lo que él llamaba «derivaciones», eran artificiales y efímeras; en cambio, los elementos constantes e irracionales eran los que configuraban lo eterno y esencia en el hombre, lo que el teórico italiano denominaba «residuo». Cfr. CAÑEQUE, C., Teorías y métodos, en M. Pastor (Coord.), Fundamentos de Ciencia Política, Madrid, McGrawHill, 2002, págs. 91-92.

10 VERNET I LLOBET ha puesto de manifiesto la coincidencia temporal entre el simbolismo, un movimiento artístico que ponía el énfasis en la transmisión de emociones profundas sin retratar la realidad, el romanticismo y el nacionalismo. Cfr. VERNET I LLOBET, J., «Símbolos y fiestas nacionales en España», Teoría y Realidad Constitucional, núms. 12-13, 2003-2004, pág. 99.

11 «La capacidad para manipular el residuo daba fundamento a la teoría de las élites, ya que los más capaces, los más aptos para dirigir a la sociedad, eran los únicos que podían moldearlo». 
La simbología de una nación está contenida de forma apriorística en la psicología colectiva y forma parte de nosotros nada más nacer. En verdad los símbolos no nos pertenecen como ciudadanos, somos nosotros los que pertenecemos a ellos, por eso funcionamos a través de los prejuicios. Como brillantemente señalaba GADAMER, «en realidad no es la historia la que nos pertenece, sino que somos nosotros los que pertenecemos a ella. Mucho antes de que nosotros nos comprendamos a nosotros mismos en la reflexión, nos estamos comprendiendo ya de una manera autoevidente en la familia, la sociedad y el estado en que vivimos» ${ }^{12}$.

Hay que subrayar que también a partir del descubrimiento de lo simbólico, el hombre se da cuenta de que existen realidades poderosas y significativas, y por tanto, realidades necesarias frente a la contingencia de la propia existencia. El homo symbolicus empieza ya a ser consciente de «la precariedad de su condición y de la incertidumbre de su destino» ${ }^{13}$. Además, los símbolos son multivalentes, siendo capaces de expresar a la vez distintas significaciones al mismo tiempo. De esta forma, el símbolo «hace una llamada a la interpretación, precisamente porque dice más de lo que no dice y de lo que jamás termina de decir» ${ }^{14}$. Igualmente, los símbolos son capaces de aportar una perspectiva en la cual «realidades heterogéneas son susceptibles de articularse dentro del todo, o incluso de integrarse dentro de un sistema» ${ }^{15}$. Pues bien, es de nuevo a esta perspectiva a la que van dedicadas estas páginas pues la cuestión de la identidad nacional, también de los símbolos nacionales, se ha planteado sobre todo entre nosotros en el contexto del debate sobre la estructura territorial ${ }^{16}$.

Cfr. MOSSE, G., La cultura europea del siglo XX, Ariel Historia, Barcelona, 1997, pág. 132. GARRORENA también señala como uno de los riesgos del recurso de las comunidades políticas a los símbolos «caldear interesadamente sus ingredientes irracionales y emotivos, lo que no es sino una forma de comunicar irracionalidad al proceso político mismo a fin de manipularlo» —loc. cit. 1020 -

12 «La lente de la subjetividad es un espejo deformante. La autorreflexión del individuo no es más que una chispa en la corriente cerrada de la vida histórica. Por eso los prejuicios de un individuo son, mucho más que sus juicios, la realidad histórica de su ser». Cfr. GADAMER, H. G., Verdad y método, I, Salamanca, Editorial Sígueme, 2001, pág. 344.

${ }^{13}$ Cfr. AGÍS VillaverDe, M. «Simbolismo y Hermenéutica. Mircea Eliade y Paul Ricoeur», Una interpretación evaluativa de nuestra cultura. Análisis y lectura del almacén simbólico de Eranos, Suplementos. Materiales de trabajo intelectual, Anthropos, Editorial del Hombre, febrero de 1994, pág. 102, que pone de manifiesto la relación entre el homo symbolicus y el bomo religiosus.

${ }^{14}$ Cfr. RICOEUR, P., "Structure et hermenéutique», en Le conflit des interprétations. Essais d’hermenéutique, París, Seuil, 1969, pág. 32.

${ }^{15}$ Cfr. AGÍS VILLAVERDE, M. ibidem, pág. 103.

${ }^{16}$ Cfr. BON P., «La identidad nacional o constitucional», REDC, núm. 100, 2014, pág. 168. Un resumen de los siguientes apartados se publicará como comentario al art. 4 y 5 de la Constitución Española en el Libro Homenaje al Profesor Luis López Guerra. 


\section{LA BANDERA}

\section{La bandera como símbolo del Estado y como elemento de integración de los ciudadanos en la comunidad y la constitucionalización de las banderas autonómicas.}

La Constitución de 1978 regula la bandera de España y las banderas y enseñas propias de las Comunidades Autónomas, en el art. 4 dentro de su Título Preliminar ${ }^{17}$. Como antecedente hay que destacar el art. 1.4 de la Constitución Española de 1931 que señalaba que «la bandera de la República española es roja, amarilla y morada». La Constitución de la II República dio una gran importancia a la bandera, al regularla en el primer precepto de la Constitución — también dentro del Título Preliminar- junto a la definición de España como una República democrática de trabajadores de toda clase que se organiza en régimen de Libertad y de Justicia, la afirmación de que todos los órganos de la República emanan del pueblo o el establecimiento de un Estado integral compatible con la autonomía de los Municipios y de las Regiones. La Constitución de 1978 modifica la forma política del Estado Español prevista en la anterior Constitución de 1931, estableciendo una Monarquía parlamentaria, lo que ha tenido reflejo también en el cambio del símbolo de la bandera.

El derecho comparado ofrece también algunos ejemplos de regulación constitucional de la bandera, junto con otros símbolos del Estado ${ }^{18}$, lo que pone de manifiesto que se trata de un bien constitucional. La Constitución Francesa regula la bandera en el mismo precepto que la lengua, el himno, la divisa de la República y sus principios nacionales — art. 2-. Igualmente, la Constitución de Portugal regula la bandera, junto con el himno y la lengua oficial — art. 11—. La Constitución Alemana regula la bandera — art. 22.2 - justo después de la capitalidad. También la Constitución italiana regula la bandera —art. 12-, así como la Constitución de Austria — art. 8.a.I-, remitiendo ésta última a la ley federal las normas de desarrollo, especialmente sobre protección de los colores, del escudo y del sello de la República.

${ }^{17}$ Cfr. MORENO LUZÓN, J. y NÚÑEZ SEIXAS, X., Los colores de la Patria: Símbolos nacionales en la España contemporánea, Tecnos, Madrid, 2017; ALZAGA VILLAAMIL, O., Comentario sistemático a la Constitución de 1978, 2. ${ }^{\circ}$ ed., Marcial Pons, Madrid, 2016, págs. 93-94; ENTRENA CUESTA, R., «Artículo 4», en GARRIDO FALLA, F. Comentario a la Constitución, 3. ${ }^{\mathrm{a}}$ ed., Civitas, Madrid, 2001, págs. 76-87; LUCA VERDÚ, P., «Art. 4. ${ }^{\circ}$ Símbolos políticos», en ALZAGA VILLAAMIL, O., Comentarios a la Constitución Española de 1978, Edersa, Madrid, 1996, I, págs. 287-294; GARRORENA MORALES, A., «Los símbolos de las Comunidades Autónomas y la función del derecho», cit. págs. 1015-1034; SOLOZABAL ECHEVARRÍA, J.J., «Comentario al art. 4», en CASAS M. E. y RODRÍGUEZ PIÑERO, M., Comentarios a la Constitución Española, XXX Aniversario, Fundación Wolters Kluwer, Madrid, 2009, págs. 74-79; id., «Nación y banderas», en RGDC, núm. 6, 2008, págs. 1-25; VERNET I LLOBET, J., loc. cit. págs. 99-122, esp. págs. 99-107.

18 Existen algunas referencias clásicas sobre los símbolos políticos. Cfr. GARCÍA PELAYO, M., «Ensayo de una teoría de los símbolos políticos», en Mitos y símbolos políticos, Obras Completas, I, CEC, Madrid, 1991, págs. 987-1031, esp. págs. 1027 y ss; STERN, K., »Símbolos y autopresentación del Estado», Derecho del Estado de la República Federal Alemana, CEC, Madrid, 1987, págs. 505-521. 
Muchos países, la mayoría de ellos caracterizados por su estabilidad o por no haber vivido recientemente cambios bruscos en su régimen político no mencionan la bandera en su Constitución: Suiza, Suecia, Luxemburgo, Dinamarca, Países Bajos, Finlandia, Malta, Bélgica ${ }^{19}$, aunque también Grecia y Polonia. En cambio, los países que formaban parte del antiguo bloque del este o que han surgido de la desintegración de la Unión Soviética han querido hacer gala en su nueva Constitución de los símbolos nacionales, regulando la bandera ${ }^{20}$ e incluso junto a ésta han incorporado otros símbolos nacionales como el escudo, el himno o el día nacional ${ }^{21}$, un fenómeno que recuerda la creación de himnos y banderas por parte de los Estados europeos durante el siglo XIX. Muchas de estas Constituciones han establecido una reserva de ley en este ámbito o han remitido íntegramente la regulación de estos símbolos a la ley posterior $^{22}$. Especial mención merece Chipre, un país donde las comunidades turcochipriota y grecochipriota han estado tradicionalmente enfrentadas, lo que ha tenido reflejo en la regulación de la bandera. Por ello la Constitución de Chipre señala que el Presidente y Vicepresidente elegirán la bandera de la República con un diseño neutral, permitiendo a autoridades y a Administraciones Públicas utilizar junto con la bandera de Chipre, la bandera de Grecia y la de Turquía siempre al mismo tiempo, reconociendo expresamente el derecho de sus ciudadanos a utilizar la bandera de Grecia o la de Turquía indistintamente sin ningún tipo de restricción —art. 4-.

La regulación en la Constitución de 1978 de la bandera dentro del art. 4 del Título Preliminar — sujeto al procedimiento agravado de reforma previsto en el art. $168 \mathrm{CE}$ - muestra también la importancia que los constituyentes quisieron dar a este símbolo. La regulación de la bandera se efectúa en los primeros preceptos de nuestra Constitución, después de la definición de nuestro Estado como social y democrático de derecho, la atribución de la soberanía nacional al pueblo español, la afirmación de que la forma política del Estado español es la de una Monarquía parlamentaria - art. $1 \mathrm{CE}$ - y la aserción de que la Constitución se fundamenta en la indisoluble unidad de la Nación española — art. 2-. De alguna manera la bandera, regulada poco después, supone el símbolo de todo lo anterior. Llama la atención que la bandera, un elemento simbólico de expresión o de comunicación no verbal, sea regulada justo después del castellano, lengua española oficial del Estado, que todos los españoles tienen el deber de conocer y el derecho a usar — art. 3-. La CE refleja una voluntad deliberada de no hacer referencias a otros símbolos nacionales — himno, escudo, día nacional, divisas_- después de una dictadura caracterizada por la exaltación de los símbolos nacionales.

19 La Constitución de Bélgica actual ha eliminado los símbolos nacionales presentes en el art. 125 del texto de 1831 .

${ }^{20}$ Cfr. art. 166 de la Constitución de Bulgaria y art. 7 de la Constitución Estonia.

${ }^{21}$ Cfr. art. I de la Constitución de Hungría, art. 12 de la Constitución de Rumanía, art. 11 de la Constitución de Croacia, art. 6 de la Constitución de Eslovenia, art. 15 de la Constitución de Lituana y art. 9 de la Constitución de Eslovaquia.

${ }^{22}$ Cfr. art. 14 de la Constitución de la República Checa. 
La regulación de la bandera en el art. 4 CE «casi no originó debate» en las Cortes Generales. La existencia en la transición política de distintas formaciones políticas que defendían o habían defendido previamente la forma de Estado republicana, y, que, consiguientemente enarbolaban la bandera tricolor como símbolo de sus reivindicaciones políticas aconsejó la regulación de la bandera en la Constitución de manera que esta cuestión simbólica quedara cerrada ya y formara parte del pacto constituyente $^{23}$. La actual bandera constitucional que restaura la de la Monarquía había sido retomada anteriormente durante la sublevación militar y posterior Dictadura del General Franco. La Ley de Sucesión en la Jefatura del Estado de 1947 señalaba que España, como unidad política, «se declara constituido en Reino» — art. 1—, estableciendo que el sucesor en la Jefatura del Estado lo hará «a título de Rey o de regente» -art. 6- ${ }^{24}$.

La bandera de España es, pues, la bandera de la monarquía. Además, existe un paralelismo entre el carácter simbólico de la bandera y el del Rey que es definido por la Constitución como el «símbolo de la unidad y permanencia del Estado» — art. 56.1- ${ }^{25}$. A diferencia de la bandera, el Rey muestra los sentimientos de los españoles — ríe cuando debe reír, llora cuando debe llorar-. Al igual que el Rey personifica a España y la lealtad al Rey — también la de los militares - es entendida como lealtad a España ${ }^{26}$, la bandera simboliza lo que España es ahora, pero también representa el recuerdo hecho presente de lo que España ha sido en su historia por el esfuerzo de las distintas generaciones de mujeres y hombres, la voluntad de continuar esta historia en común ${ }^{27}$, el respeto «a todos los españoles y pueblos de España en el

${ }^{23}$ Cfr. AlZaga VillaAmil, O., Op. cit. pág. 93.

${ }^{24}$ Hay que reconocer la generosidad y el sentido de responsabilidad del Partido Comunista de España en la aceptación de la Monarquía parlamentaria como forma política del Estado Español, y, por tanto, también de la bandera que había sido empleada durante el régimen anterior. Señalaba J. SOLÉ TURA en el debate constituyente que «un partido político que se propone transformar la sociedad no puede prescindir de la realidad; si en las condiciones concretas de España - y yo añadiría aquí y abora - se pusiese sobre el tapete la cuestión de la República, correríamos una aventura catastrófica en la que seguro que no tendríamos República, pero perderíamos la democracia. Tal riesgo podría correrle un grupo político que no se proponga hacer política, pero un partido serio y responsable, dispuesto a hacer avanzar la democracia y convertirse una fuerza de gobierno, no puede lanzar al país a esa aventura». Cfr. Diario de Sesiones del Congreso de los Diputados, Comisión de Asuntos Constitucionales, núm. 61, sesión n. ${ }^{\circ}$ 3, 9 de mayo de 1978, pág. 2109. También menciona la generosidad de las fuerzas de la izquierda SOLOZABAL ECHEVARRÍA, J. J., «Comentario al art. 4», loc. cit.pág. 77.

${ }^{25}$ STERN señala que tanto los símbolos como la bandera están extraordinariamente cerca de la representación y ambos tienen una función integradora común, aunque deben ser distinguidos: la representación se efectúa a través de personas; los símbolos se hacen presentes la mayor de las veces mediante signos. Cfr. STERN, K., op. cit. págs. 508-509.

${ }^{26}$ Así, en el Reglamento de Honores Militares, aprobado por el Real Decreto 684/2010, de 20 de mayo, los honores a la bandera son semejantes a los del Rey - arts. 4 y 8 -

${ }^{27}$ Cfr. LUCAS VERDÚ, P., loc. cit. pág. 289. Para GARRORENA MORALES, A, los símbolos «son acumuladores del pasado y contiene la memoria colectiva del grupo, al tiempo que expresan la voluntad presente de los individuos que lo forman de prolongar juntos ese pasado común» —loc. cit. pág. 1018—. 
ejercicio de sus derechos humanos, sus culturas y tradiciones, lenguas e instituciones» —Preámbulo de la Constitución_-, que también conforma el juramento del Rey al ser proclamado ante las Cortes Generales — art. 61.1 CE_- Por tanto, la bandera es también símbolo de la unidad y permanencia del Estado. En esta dirección, la Ley $39 / 1981$, de 28 de octubre, por la que se regula el uso de la bandera de España y el de otras banderas y enseñas, señala que «la bandera de España simboliza la nación; es signo de la soberanía, independencia, unidad e integridad de la patria y representa los valores superiores expresados en la Constitución» — art. 1—. Igualmente la Constitución de Portugal establece que la bandera nacional es el «símbolo de la soberanía de la República y de la independencia, unidad e integridad de Portugal» -art. 11.1-.

El art. 4.1 CE señala que «la bandera de España está formada por tres franjas horizontales, roja, amarilla y roja, siendo la amarilla de doble anchura que cada una de las rojas». Esta bandera de España, con las características actuales, lleva ondeando más de dos siglos en virtud de un Real Decreto de Carlos III el 28 de mayo de 1785. El Rey convocó un concurso de diseño de banderas navales para sustituir la bandera blanca que llevaba el escudo de armas reales, señalando este Real Decreto como razón «para evitar los inconvenientes y perjuicios que ha hecho ver la experiencia puede ocasionar la Bandera Nacional que usa mi Armada Naval y demás embarcaciones Españolas, equivocándolas a largas distancias o con vientos calmosos con las de otras Naciones» ${ }^{28}$. Finalmente fue el propio Rey el que compuso una bandera diferente en la que la franja central amarilla era el doble de ancho que las de los extremos en rojo. Posteriormente un Real Decreto de Carlos IV de 8 de marzo de 1793 amplió el uso de esta bandera roja y amarilla a las plazas marítimas, castillos y defensas de las costas. Finalmente un Real Decreto de 13 de octubre de 1843, aún durante el periodo de Regencia, extendió esta bandera a todas las enseñas de los ejércitos $^{29}$. Sin embargo esta bandera no era inicialmente la de la Monarquía porque los Reales Decretos antes citados, al referirse a ella, utilizan la expresión «bandera nacional» existiendo además un Pendón Real que sí era privativo del Rey y que,

${ }^{28}$ Cuando el calibre y el alcance de la artillería naval obligaron a los buques a combatir cada vez a mayores distancias, la bandera «fue empequeñeciéndose y haciéndose menos distintiva», además de que otras monarquías de la Casa de Borbón enarbolaban banderas blancas aunque con escudos diferentes. «En algún momento debió de cometerse alguna trágica equivocación y comenzó a pensarse en modificar el cromatismo de la bandera». Todavía en las Ordenanzas de la Armada de Fernando VI de 1748 se decía: «Por ahora usarán todos los navíos de la Armada la bandera nacional ordinaria, con el escudo de mis Armas, hasta que Yo tenga a bien disponer otra cosa». Cfr. GRAVALOS GONZÁleZ, L., «La bandera», Péndulo. Revista de Ingeniería y Humanidades, núm. 19, 2008, págs. 35-36 y 41. Cfr. también O’DONELL Y DUQUE DE ESTRADA, H., «La bandera. Su significado a lo largo de la historia», en AA.VV. Símbolos de España, Centro de Estudios Constitucionales, Madrid, 2010.

29 El 8 de noviembre de 1843 las Cortes decidieron adelantar la mayoría de edad de la Reina Isabel II, que juró la Constitución el 10 de noviembre de 1843 . 
curiosamente, en época de Isabel II era de color morado ${ }^{30}$. Esta ha sido la bandera de España hasta la actualidad, sólo interrumpida durante la etapa de la II República, en virtud de la previsión ya citada del art. 1.4 de la Constitución Española de 1931. Hay que señalar que el Decreto de aprobación de 27 de abril de 1931 introducía el nuevo color de esta manera: «Hoy se pliega la bandera adoptada como nacional a mediados del siglo XIX. De ella se conservan los dos colores y se le añade un tercero, que la tradición admite por insignia de una región ilustre, nervio de la nacionalidad, con lo que el emblema de la República, así formado, resume más acertadamente la armonía de una gran España». Aunque el origen de la franja morada en la bandera republicana es bastante controvertido y equívoco, es posible que los republicanos de principio del siglo xx creyesen que Castilla no estaba representada en la enseña nacional por faltar el color morado ya que el color amarillo y rojo carmesí estaban atribuidos a Aragón ${ }^{31}$. De esta forma, se apartaban también simbólicamente de la bandera de la I República y ponían de manifestó que para estos republicanos, tal vez distintos a los de ahora, Castilla era fundamental para vertebrar la nueva República y regenerar España.

La descripción de la bandera de España presente en el art. 4.1 CE, aun siendo la misma bandera, se separa de la recogida en el art. 5 de la Ley 1/1967, de 10 de enero, Orgánica del Estado, que establecía que «la bandera nacional es la compuesta por tres franjas horizontales: roja, gualda y roja; la gualda, de doble anchura que las rojas» ${ }^{32}$. Se produce una modificación de la descripción de este símbolo que es también significativa. La anterior bandera nacional es ahora la bandera de España, en la que junto a la Nación española, tal como aparece al comienzo del Preámbulo de nuestra Constitución, patria común e indivisible de todos los españoles, coexis-

${ }^{30}$ Cfr. ÁLVAREZ ABEILHÉ, J., La bandera de España, Instituto de historia y cultura militar, disponible desde Internet en: http://www.ejercito.mde.es/unidades/Madrid/ibycm/Actividades/CiclosDivulgativos/vexi-historia-bandera.btml, [con acceso el 7 de mayo de 2108].

${ }^{31}$ Para M. NÚÑEZ DÍAZ-BALART, el color morado era una «reivindicación de los comuneros castellanos del siglo XVI, que fueron la voz del pueblo contra la tiranía del poder». En la misma dirección M. MÁRQUEZ PADORNO señalaba que «el Pacto de San Sebastián, que reunió el 17 de agosto de 1930 al movimiento republicano español, tomará de los Hijos de Padilla del Trienio liberal el color morado de la banda que utilizaban como símbolo. Además, algunos batallones del Ejército en Castilla ataban a sus banderas o estandartes corbatas o cintas moradas». Apud LLONA, G., «El origen daltónico de la bandera republicana», Diario $A B C, 30$ de abril de 2012, disponible desde internet en: http://www.abc.es/20120413/espana/abci-bandera-republicana-colores-201204122103.html, [con acceso el 5 de mayo de 2018].

Sin embargo, como señala Álvarez Abeilhé, J., «el Pendón de Castilla no es morado, sino carmesí. La confusión existente acerca del color del pendón castellano nació en el siglo XIX, cuando una de las múltiples sociedades secretas, que tanto proliferaron en aquella época, tomó el nombre de «Comuneros» y adoptó el color morado como distintivo, sin que tuvieran ninguna relación con los verdaderos Comuneros que, cuatro siglos antes, habían enarbolado el pendón carmesí en Villalar» —ibidem-.

32 El Decreto de 29 de agosto de 1939, aprobado por la Junta de Defensa Nacional, restablecía «la bandera bicolor, roja y gualda como bandera de España». 
ten distintas nacionalidades — art. 2 CE— ${ }^{33}$. Además, el color ya no es definido como gualda sino como amarillo, después de una enmienda conocida del Senador Cela ${ }^{34}$. De esta forma, manteniéndose idéntico el símbolo, existe una voluntad de incluir una definición discreta de la bandera, apartándose deliberadamente de la adjetivación simbólica del régimen anterior. La Ley 39/1981, de 28 de octubre reitera lo preceptuado en el art. 4.1 CE, añadiendo que «en la franja amarilla se podrá incorporar, en la forma que reglamentariamente se señale, el escudo de España»—art. 2.2- ${ }^{35}$.

La bandera es el símbolo que representa a España, patria común e indivisible de todos los españoles — art. 2-. La patria es la «tierra natal o adoptiva ordenada como nación, a la que se siente ligado el ser humano por vínculos jurídicos, históricos y afectivos», el «lugar, ciudad o país en que se ha nacido» — drae—. Por tanto, la bandera, al emplearse como «enseña o señal de una nación», transmite también un significado de pertenencia y de identidad colectiva. Es un símbolo de integración. Como señala LuCAS VERdú, la bandera cumple una función de facilitar la integración simbólica de los ciudadanos en el Estado porque la naturaleza humana «no solo es racional sino sentiente que requiere una integración en la comunidad nacional a través de símbolos» ${ }^{36}$. Así, por encima del pluralismo existente en nuestro país - político, territorial, de clase social, de cultura o de generaciones_-, la bandera como símbolo que representa a España ayuda a trascender e ir más allá de las discrepancias y de las divisiones, teniendo en cuenta sobre todo lo que nos une. La reivindicación de la bandera, su uso social fuera del ámbito de las Administraciones Públicas, refleja un elemento de psicológico de pertenencia, de orgullo colectivo, de integración voluntaria y consciente en la comunidad a través de la exhibición de

33 VERNET I LLOBET, J. — loc. cit. pág. 105- señala que el adjetivo nacional estaba presente en algunas enmiendas al proyecto de Constitución que fueron rechazadas por lo que «bandera nacional y bandera de España no deben considerarse expresiones análogas», aunque como ya hemos señalado el art. 1 de la Ley 39/1981 de 5 de octubre establece que «la bandera de España simboliza la nación».

34 «Gualda, evidentemente, es castellano, sí, aunque de origen bárbaro y uso no demasiado extendido». Este adjetivo provenía de una canción militar, en la que se había sustituido la referencia al color amarillo por el gualda por razones métricas y su empleo daba al precepto constitucional un regusto patriotero que no aportaba nada positivo. Cfr. ENTRENA CUESTA, R., loc. cit. pág. 77; ALZAGA VILLAAMIL, O., op. cit. pág. 94.

${ }^{3}$ Cfr. la Ley 33/1981, de 5 de octubre, del Escudo de España, el Real Decreto 2964/1981, de 18 de diciembre, por el que se hace público el modelo oficial del Escudo de España y el Real Decreto 2267/1982, de 3 de septiembre, por el que se especifican técnicamente los colores del Escudo de España.

36 Cfr. LUCAS VERDÚ, P., loc. cit. pág. 289. SMEND subraya la eficacia integradora que los símbolos políticos cumplen en el Estado, que se debe no sólo a su propia naturaleza irracional sino a que el símbolo es siempre más moldeable que las fórmulas racionales y legales: «los contenidos valorativos simbolizados pueden ser vividos personalmente tal y como yo los entiendo, sin la tensión y el rechazo que necesariamente producen fórmulas y reglamentaciones»-SMEND, R., op. cit. pág. 98-. 
su símbolo. Si bien durante la transición y los primeros años de democracia el uso social de la bandera fue realizado principalmente por una minoría de extrema derecha, progresivamente esto se fue superando — también políticamente- de forma que la bandera refleja hoy el pluralismo político del régimen constitucional de 1978. Aunque en apariencia pueda parecer algo anecdótico, los deportes - especialmente el futbol — han sido una oportunidad para un uso popular espontáneo de la bandera, como elemento simbólico de integración y sin un significado político ${ }^{37}$. Recientemente, se ha producido una presencia masiva de la bandera española en los balcones, en este caso con un claro sentido político, como elemento de defensa de la unidad de España y de reivindicación de la Constitución Española y de las libertades de todos, también de los ciudadanos catalanes, ante el problema de libertad que ha supuesto la declaración unilateral de independencia del Parlamento de Cataluña.

$\mathrm{El}$ art. 4.2 CE establece que «los Estatutos podrán reconocer banderas y enseñas propias de las Comunidades Autónomas. Estas se utilizarán junto a la bandera de España en sus edificios públicos y en sus actos oficiales». Se trata de una previsión novedosa que no tiene antecedentes en nuestra historia constitucional ni correspondencia en el Derecho constitucional comparado ${ }^{38}$ y que supone «la constitucionalización de las enseñas autonómicas» y el establecimiento de una reserva de estatuto y de una obligación de utilización conjunta de las banderas y enseñas autonómicas junto a la bandera de España en edificios públicos y actos oficiales ${ }^{39}$. Es la propia Constitución la que se abre a la existencia de banderas y enseñas de las Comunidades Autónomas — de las nacionalidades a las que se refiere el art. 2 CE—, previendo no sólo su reconocimiento en los Estatutos de Autonomía sino su uti-

37 GONZÁLEZ RAMALLAL analiza el futbol desde la perspectiva de las identidades colectivas: «En buena parte del imaginario social de España permanece aún esta idea en la que el Real Madrid Club de Futbol encarna a una nación centralizada y unificada en torno a la capital del Estado, a la que le cuesta reconocer otras expresiones identitarias diferentes a las que emanan de esta idea de nación. Estas manifestaciones de una identidad particular se exteriorizan a menudo en el terreno futbolístico y mediático. [...] En el caso del Futbol Club Barcelona tenemos un ejemplo paradigmático de sublimación de la identidad a través de una institución deportiva. Ese «más que un club» refleja las aspiraciones de buena parte del pueblo catalán de constituirse como nación, así las victorias deportivas son vividas como victorias políticas, mientras que las derrotas suponen una sentimiento de frustración por no haber podido o sabido articularse como Estado». Cfr. GONZÁLEZ RAMALLAL, M. E., «Prensa deportiva e identidad nacional. España en el Mundial de fútbol de Sudáfrica 2010», Política y sociedad, vol. 54, núm. 2, 2014, pág. 347, citando a COLOMÉ, G., «Conflictos e identidades en Cataluña», en SEGUROLA, S., (ed.), Fútbol y pasiones políticas, Debate, Madrid, 1999.

${ }_{38}$ STC 94/1985, de 29 de julio, F. J. 6. .

39 No se trata, pues, de una remisión en blanco al estatuyente. Cfr. SOLOZABAL ECHEVARRÍA, J. J., «Comentario al art. 4», loc. cit.págs. 77-78. Para GARRORENA MORALES, A, el art. 4.2 CE consagra dos principios básicos: el principio de constitucionalidad de las banderas autonómicas, en virtud del cual éstas tienen un status constitucional; y el principio de concurrencia con la bandera de España, según el cual las banderas de las CC.AA no pueden utilizarse oficialmente si no es junto con la bandera del Estado, reconociendo a la misma la debida precedencia —loc. cit. pág. 1025_. 
lización junto a la bandera de España en edificios públicos y actos oficiales. Si bien la bandera de España es la de todos los pueblos de España y abarca todas las nacionalidades y regiones, la previsión del art. 4.2 CE es «una forma de expresión a través de los símbolos de la organización del Estado en Comunidades Autónomas» ${ }^{40}$. Como expresión del espíritu de consenso que caracterizó nuestra transición política, el constituyente trató que la utilización de las banderas de las Comunidades Autónomas fuera un elemento de integración de una España plural, al igual que hizo con el reconocimiento de la oficialidad de las lenguas de las Comunidades Autónomas y con la afirmación de que la riqueza de las distintas modalidades lingüísticas es un patrimonio cultural que merece especial objeto y protección - art. 3.2 y $3 \mathrm{CE}$ - , todo ello en línea con la consideración de que «la indisoluble unidad de la Nación española, patria común e indivisible de todos los españoles» no es obstáculo para reconocer y garantizar «el derecho a la autonomía de la nacionalidades y regiones que la integran y la solidaridad entre todas ellas» — art. 2 CE_- Se trataba, como señalaba PÉrEz-LlorCA, de una apuesta porque los sentimientos autonomistas, al igual que sus símbolos, si se encauzaban, llegasen a ser un factor de integración más que de separación ${ }^{41}$. En esta dirección también se había manifestado SolÉ Tura en el debate constituyente: «Hay que decir las cosas con toda claridad. España es una realidad multiforme, pero es una realidad y es tarea de todos hacer que incluso sus propios símbolos, sean reconocidos como tales» ${ }^{42}$.

40 Como señala la STC 119/1992, de 18 de septiembre, «el problema no estriba en determinar cuáles son, deben ser o pueden ser los símbolos y emblemas de la Nación o Estado español. Resulta indudable, a la vista del art. 2 de la Constitución, que la misma ha instaurado un Estado complejo, en el que el ejercicio de las funciones estatales se encomienda tanto a las instituciones generales del Estado como a las Comunidades Autónomas, dotadas de autonomía política que son expresión del «derecho a la autonomía de las nacionalidades y regiones» que integran «la Nación española, patria común e indivisible de todos los españoles». Sin necesidad de insistir en el sentido anfibológico con el que el término Estado se utiliza en la C.E. (SSTC 32/81 y 38/82), no cabe duda de que, siendo los principales símbolos de nuestro Estado la bandera de España y su escudo, también son símbolos del Estado español las banderas y enseñas previstas en el art. 4 C.E. y reconocidas en los Estatutos de las CCAA, en tanto en cuanto, como ha quedado dicho, éstas constituyen la expresión de la autonomía que la Constitución ampara y de la pluralidad y complejidad del Estado que configura» -F. J. 1. ${ }^{\circ}-$.

${ }^{41}$ Cfr. PÉreZ llORCA, J. P., ABC el 11 de enero de 1978. Apud ALZAGA VILLAAMIL, O., Comentario sistemático a la Constitución de 1978, cit. pág. 78. Como señala Ortega, «entorpece sobremanera la inteligencia de lo histórico suponer que cuando de los núcleos inferiores se ha formado la unidad superior nacional, dejan de existir aquellos como elementos activamente diferenciados». Cfr. ORTEGA Y GASSET, J., España invertebrada, cit.pág. 23.

42 Así, SOLÉ TURA, en la discusión del art. 2 CE, hablando «como comunista que expresa un punto de vista de los comunistas de toda España y como catalán», subrayó que «la singularidad de Cataluña, como la singularidad de dar las nacionalidades y regiones de España, es perfectamente compatible no solo con el concepto de unidad de España, que es precisamente su corolario, sino también con sus símbolos». Cfr. Diario de Sesiones del Congreso de los Diputados, cit. pág. 2110. 


\section{Los conflictos por el uso de las banderas: la guerra de las banderas}

España ha sufrido durante su historia distintas crisis en el sentido de pertenencia a esa Nación, patria común e indivisible de todos los españoles, también en las etapas más recientes, derivadas especialmente de nuestra diversidad territorial. Esto se ha manifestado en las dificultades para aceptar la bandera como un símbolo propio, lo que se ha materializado en conflictos por el uso de las banderas que ha dado lugar a múltiples Sentencias. La bandera deja de ser un elemento de integración para convertirse también en un elemento de diferenciación, que separa a los que la usan porque se sienten identificados, integrados y representados por ella y a los que no lo hacen, «el nosotros y el ellos» ${ }^{43}$. En ocasiones, la exposición de la bandera no sólo da lugar a un sentimiento de indiferencia por representar a una comunidad distinta sino de antagonismo o de hostilidad, cuando se trata de una comunidad históricamente enfrentada a la que se considera propia, cargando de connotaciones negativas los símbolos de los otros ${ }^{44}$.

Por tanto, vamos a analizar distintos conflictos a los que ha dado lugar el uso de las banderas — la llamada guerra de las banderas — : en primer lugar, la obligación de utilizar la bandera de España en edificios públicos y actos oficiales y sus incumplimientos; en segundo lugar la bandera como bien jurídico merecedor de protección penal y el cuestionamiento del delito de ultraje a la bandera como límite a la libertad de expresión; en tercer lugar, la prohibición de la exhibición en edificios públicos de banderas partidistas y de la utilización de la bandera de España o de las enseñas auto-

43 Cfr. MORENO LUZÓN, J. y NÚÑEZ SEIXAS, X., op. cit. págs. 17-25, esp. pág. 20. En esta dirección GARRORENA explica como los símbolos cumplen una función de identificación de la realidad simbolizada en la medida en que los símbolos la equivalen y una función de identificación con dicha realidad, es decir, son un vehículo de reconocimiento de pertenencia a ella. Cfr. GARRORENA MORALES, A, loc. cit. pág. 1018.Como señala la STC 94/1985, de 29 de julio, «no puede desconocerse que la materia sensible del símbolo politico [...] trasciende a sí misma para adquirir una relevante función significativa. Enriquecido con el transcurso del tiempo, el símbolo político acumula toda la carga histórica de una comunidad, todo un conjunto de significaciones que ejercen una función integradora y promueven una respuesta socioemocional, contribuyendo a la formación y mantenimiento de la conciencia comunitaria, $\mathrm{y}$, en cuanto expresión externa de la peculiaridad de esa Comunidad, adquiere una cierta autonomía respecto de las significaciones simbolizadas, con las que es identificada; de aquí la protección dispensada a los símbolos políticos por los ordenamientos jurídicos. Al símbolo político corresponde, pues, al lado de una función significativa integradora, una esencial función representativa e identificadora, que debe ejercer con la mayor pureza y virtualidad posibles» - F. J. 7.﹎- También SOLOZABAL destaca que los símbolos políticos son un medio de identificación del individuo con la colectividad y un instrumento de movilización. Cfr. SOLOZABAL ECHEVARRÍA, J.J., «Comentario al art. 4», loc. cit. pág. 75.

${ }^{44}$ Cfr. GARCÍA PELAYO, M. diferencia dentro de los símbolos ajenos los símbolos indiferentes - para los que somos insensibles por ser las banderas de países con los que no hemos tenido ningún contacto - y los antagónicos o adversarios, frente a los que nos sentimos en enemistad política y que su mera exhibición exacerba nuestro antagonismo — loc. cit. págs. 93-94-; REBOLLO VARGAS, R, «Bases para una interpretación crítica del delito de ultrajes a España», Estudios penales y criminológicos, vol. XXXIV, 2014, págs. 84-85. 
nómicas como símbolo oficial de un partido político o de una candidatura; y, finalmente, en cuarto lugar, los conflictos por la utilización de las banderas de las Comunidades Autónomas.

a) La obligación de utilizar la bandera de España en edificios públicos y actos oficiales y sus incumplimientos

El art. 4.2 CE establece que las banderas y enseñas propias de las Comunidades Autónomas «se utilizarán junto a la bandera de España en sus edificios públicos y en sus actos oficiales», lo que supone, como hemos señalado antes, el establecimiento de una obligación constitucional en este sentido. La Ley 39/1981, de 28 de octubre recoge que la bandera de España — en la que figurará obligatoriamente el escudo de España«deberá ondear en el exterior y ocupar el lugar preferente en el interior de todos los edificios y establecimientos de la Administración central, institucional, autonómica, provincial o insular y municipal del Estado», además de ser la única que ondee y se exhiba en las sedes de los órganos constitucionales del Estado, órganos centrales de la Administración del Estado, edificios públicos, acuartelamientos de Fuerzas Armadas y de la Seguridad del Estado, misiones diplomáticas y oficinas consulares —arts. 2 y 3-. Además, «la bandera de España ocupará siempre lugar destacado, visible y de honor. Si junto a ella se utilizan otras banderas, la bandera de España ocupará lugar preeminente y de máximo honor y las restantes no podrán tener mayor tamaño» - art. 6-.

Sin embargo, esta legislación sobre la bandera no fue siempre respetada. La bandera era vista todavía en algunos lugares como un símbolo de la dictadura y del centralismo ${ }^{45}$ y no como el símbolo de una España constitucional, democrática, que reconoce un alto nivel de autogobierno a sus nacionalidades y regiones. La STS 2617/1988, de 14 de abril, en relación con el incumplimiento por el Ayuntamiento de Bilbao del requerimiento del Gobierno Civil para que figure la enseña nacional junto con la de la Comunidad Autónoma y la del propio Municipio en el exterior de la Casa Consistorial, subrayó que el art. 4 CE es «efecto y reflejo del contenido del art. 2 -que proclama la indisoluble unidad de la Nación Española, Patria común e indivisible de todos los españoles-». La Sentencia, auténtico leading case en esta materia, señala que la formulación del art. 4.2 CE «debería haber bastado para el adecuado uso de la bandera», si bien «las reticencias de unos grupos y la inadecuada utilización de ella como símbolo de la Nación por otros, así como las situaciones conflictivas surgidas hizo necesario el desarrollo legislativo de esta materia». Como señala la Sentencia, la Ley 39/1981, de 28 de octubre

${ }^{45}$ Señalaba SOLÉ TURA que «es cierto que hay dificultades, para qué ignorarlas; es cierto que existen, porque durante mucho tiempo los símbolos de ese Estado han sido símbolos de opresión, pero es tarea de todos terminar esa concepción, con esa visión, y hacer que esos símbolos sean considerados por todos como cosa propia» —loc. cit. pág. 2110—. 
utiliza expresiones gramaticales en sentido imperativo — será la única que ondee, se colocará, se enarbolará- «para expresar una idea o un contenido normativo de naturaleza permanente y no esporádica». Por tanto, existe una «exigencia legal de que la bandera de España ondee todos los días y en los lugares que expresa», todo ello como «símbolo que los edificios o establecimientos de las Administraciones Públicas del Estado son lugares en donde se ejerce directa, o delegadamente, la soberanía y en ellos se desarrolla la función pública en toda su amplitud e integridad, sea del orden que fuere, de acuerdo con los valores, principios, derechos y deberes constitucionales que la propia bandera representa, junto con la unidad, independencia, soberanía e integridad territorial del Estado Español. Por ello, la utilización de la bandera de España en dichos edificios o establecimientos debe de serlo diariamente como manifestación, frente a los ciudadanos, de contenido que simboliza y representa»-F. J. 2. ${ }^{\circ}$ -

Hay que subrayar que con la aprobación de la Ley 39/1981, de 28 de octubre, que desarrolla el art. 4 CE y la STS 2617/1988, de 14 de abril se comenzó a superar en gran medida la ausencia de la bandera de España en edificios públicos del País Vasco y de Cataluña. A partir del año 1996 se inició un proceso de renacionalización de España a través de sus símbolos, ya que anteriormente gobiernos de distinto signo con frecuencia habían pasado por alto algunas situaciones de incumplimiento para evitar problemas ${ }^{46}$. De hecho, la STS 5429/2007, de 24 de julio tuvo que clarificar la cuestión de si existe o no extratemporaneidad de la interposición de la demanda cuando la situación que se denunciaba venía sucediendo desde bastante tiempo, al resolver un recurso de casación promovido por el Gobierno Vasco en relación con el incumplimiento de esta obligación por la Academia de Policía Vasca de Arkaute. Frente a la alegación de la «extratemporaneidad» por parte del Gobierno Vasco — ya que «la bandera española llevaba sin ondear en la academia de policía más de veinte años, que tal cambio de criterio provocaría cierta inseguridad jurídica» y que en dicho largo plazo se ha tenido conocimiento suficiente de la situación y nunca ha sido denunciada-, el Tribunal Supremo señala que la actuación administrativa continuada no puede consolidarse al margen de la legalidad vigente y que la situación de inseguridad jurídica no proviene de la exigencia del cumplimiento de la Ley sino de la situación anterior. Por lo tanto, no cabe la extratemporaneidad del recurso por tener esta práctica una continuidad en el tiempo. La STS 5429/2007, de 24 de julio establece que «estándose en una actividad e incumplimiento continuados, tal plazo permanece abierto mientras la situación — de ilegalidad, como veremos— continúe o permanezca» —F. J. 3. - - La Ley 39/1981, de 28 de octubre establece un imperativo categórico en relación con la presencia de la bandera, sin que sea necesario, como señala la posterior STS $6564 / 2008$, de 2 de diciembre, ni siquiera un requerimiento previo del incumpli-

46 La expresión renacionalizar España a través de los símbolos así como el análisis de este proceso se encuentra en MORENO LUZÓN, J. y NÚÑEZ SEIXAS, X., op. cit. págs. 383-386. 
miento para el acceso a la vía jurisdiccional, dejando claro que el verdadero contenido del recurso es la inactividad permanente en la ejecución de lo que establece la Ley de Banderas por parte, en este último caso, de las Juntas Generales de Vizcaya. Todo ello ha facilitado al TSJ del País Vasco hacer ejecutar la legalidad en materia de banderas ${ }^{47}$.

En ocasiones se ha llevado a cabo una ejecución fraudulenta de las Sentencias que exigían el cumplimiento de la Ley, desvirtuando la obligación impuesta por éstas, al proclamar expresamente, al mismo tiempo que se cumple el mandato, que se está en contra. Buena muestra de ello es la colocación por las Juntas Generales de Guipúzcoa, junto con la bandera de España situada en el lugar legalmente asignado, de una placa con la siguiente inscripción: "he abi la bandera, símbolo de esta situación, puesta; por quien no desea hacerlo, a la que el viento ondea con ironía». La STS 7725/2011, de 17 de noviembre, que resolvió el recurso de casación ante la desestimación del recurso en la Sala de Instancia, afirma la ejecución fraudulenta de la anterior sentencia de la misma Sala, alegando que el derecho a la tutela judicial efectiva comprende la ejecución de los fallos judiciales y, en consecuencia, su presupuesto lógico es el principio de inmodificabilidad o de intangibilidad de las resoluciones judiciales firmes y de las situaciones jurídicas por ellas declaradas, porque en caso contrario «las decisiones judiciales serían meras declaraciones de intenciones» ${ }^{48}$. Así, la placa en cuestión no sólo modifica la Sentencia sino que además, con la inscripción, se quiere obtener la finalidad contraria a la pretendida por la Sentencia, contraviniendo el pronunciamiento del fallo, siendo consecuentemente una ejecución fraudulenta de tipo material. La Administración procede formalmente a la ejecución de la sentencia dictada pero lleva a cabo al mismo tiempo una actividad material que contraviene el pronunciamiento del fallo por lo que el resultado no conduce justamente a la finalidad establecida por la Ley. A consecuencia de esta Sentencia, las Juntas Generales de Guipúzcoa dictaron un Resolución en la que afirmaban no estar de acuerdo con la obligación de colocar la bandera española ya que se trata de una imposición inadmisible que va en contra de los sentimientos de la mayoría de los guipuzcoanos, Resolución que ha sido anulada por la STS 2403/2016, de 7 de junio.

b) La protección penal de la bandera y su cuestionamiento como límite a la libertad de expresión.

Una cuestión también polémica ha sido la protección penal de la bandera. El antecedente inmediato de la actual regulación penal es el art. 123 del Código Penal

${ }^{47}$ Cfr. STSJ PV 1931/2015, de 30 de junio en relación con el incumplimiento del Ayuntamiento Gámiz-Fika.

${ }^{48}$ Cfr. SSTC 20/2010, de 27 de abril -F. J 4. ${ }^{\circ}$-; 37/2007, de 12 de febrero -F. J. 4. ${ }^{\circ}-\mathrm{y}$ 86/2005, de 18 de abril, —F. J. 2. ${ }^{\circ}$-.

N. ${ }^{\circ} 103$, septiembre-diciembre 2018, págs 29-76 
de 1944 — «Delito de ultrajes a la Nación española»—, reformado en 1967 para darle una nueva redacción a este precepto, que decía: «Los ultrajes a la Nación española o al sentimiento de su unidad, al Estado o a su forma política, así como a sus símbolos y emblemas, se castigarán con la pena de prisión menor, y si tuvieren lugar con publicidad, con la de prisión mayor».

La Ley 39/1981, de 28 de octubre contenía dos preceptos —arts. 10.3 y 10.2 que fueron declarados inconstitucionales por las SSTC 118/1992 y 119/1992, de 16 y 18 de noviembre respectivamente en virtud de dos cuestiones de inconstitucionalidad planteadas por el Tribunal Supremo y por la Audiencia Provincial de Valencia. En la Sentencia 118/1992, de 16 de noviembre, el Tribunal Constitucional señalaba que la previsión del art. $10.3^{49}$ no contenía una remisión constitucionalmente válida que se extendiera únicamente a la descripción de los supuestos de hecho penalmente ilícitos sino un tipo penal ampliado ya que estaba coligando todas las actuaciones de este tipo penal con el agravante de publicidad, se cometieran o no con dicha publicidad. Esta ampliación del tipo penal era inconstitucional por ser contraria al art. 81.1 CE en relación con los arts. 17.1 y 25.1 CE, que exige reserva de Ley Orgánica para sanciones o penas privativas de libertad. En la Sentencia 119/1992, de 18 de noviembre, el Tribunal Constitucional señalaba que el art. $10.2^{50}$ era inconstitucional, de nuevo, por no revestir la Ley 39/1981, de 28 de octubre, la forma de Ley orgánica, por lo que no podía extender a los símbolos de las Comunidades Autónomas la protección penal que el art. 123 del Código Penal otorgaba a los símbolos del Estado. El legislador pretendía llevar a cabo una ampliación del tipo penal, sin acudir a la vía directa de reformar el Código Penal. El art. 10.1 de la Ley 39/1981, de 28 de octu$b_{r e}{ }^{51}$, que fue también impugnado, no fue considerado inconstitucional y permanece en vigor, porque no refleja un mandato jurídico concreto sino que se remite únicamente «a lo dispuesto en las leyes», de manera que es irrelevante desde la perspectiva penal y válido constitucionalmente.

El Código Penal vigente, aprobado por LO 10/1995, de 23 de noviembre contiene dentro del Título XXI del Libro II -Delitos contra la Constitución-, el Capítulo VI denominado «De los ultrajes a España» que alberga un único precepto, el art. 543, donde se señala: «Las ofensas o ultrajes de palabra, o por escrito o de hecho a España, a sus Comunidades Autónomas o a sus símbolos o emblemas, efectuados con publicidad, se castigarán con la pena de multa de siete a doce meses». Este precepto que considera ultrajes a España los efectuados a sus símbo-

49 «Los ultrajes y ofensas a las banderas a que se refiere el artículo tercero de esta ley, se considerarán siempre como cometidas con publicidad a los efectos de lo dispuesto en el citado artículo ciento veintitrés del Código Penal».

50 «Las infracciones de lo previsto en esta ley se considerarán incursas en lo establecido en el artículo ciento veintitrés y concordantes del Código Penal y, en su caso, en el artículo trescientos dieciséis del Código de Justicia Militar, sin perjuicio de las sanciones administrativas que pudieran proceder».

51 «Los ultrajes y ofensas a la bandera de España y a las contempladas en el artículo 4 del presente texto, se castigarán conforme a lo dispuesto en las leyes». 
los, modifica la regulación anterior: por una parte, amplía los bienes jurídicos protegidos extendiendo la protección a las Comunidades Autónomas; por otra parte, limita la conducta tipificada ya que no castiga las ofensas o ultrajes efectuados sin publicidad, además de establecer una pena más proporcionada a la que existía anteriormente ${ }^{52}$. Este precepto penal no castiga la no colocación de la bandera de España en un edificio público, que no sería una conducta tipificada en este delito, sin perjuicio del delito de desobediencia a la autoridad cuando exista una orden expresa en este sentido. Tampoco la Ley 39/1981, de 28 de octubre prevé ninguna infracción administrativa por el incumplimiento de la obligación de utilización de la bandera de España en edificios públicos y actos oficiales establecido en esta Ley ${ }^{53}$.

El art. 543 del Código Penal es objeto de discusión por parte de la doctrina penalista por la dificultad de determinar cuál es el bien jurídico penal protegido ${ }^{54}$. En el pasado se consideraba que el bien jurídico protegido era el honor nacional, ya que el antecedente de este precepto penal es el «delito contra la patria» de la Ley de Jurisdicciones de 1906, aprobada durante el Reinado de Alfonso XIII, que tenía una evidente intención antinacionalista al castigar las ofensas orales o escritas contra nación, la bandera o el himno nacional y que atribuía a la justicia militar la competencia para enjuiciar los delios de injurias al ejército, protegiendo de esta forma el sentimiento nacional o patriótico frente al nacionalismo catalán y vasco. Si bien hay una parte de la doctrina que considera necesario este tipo penal sobre todo para conductas que pongan en peligro el orden público y la paz pública y la jurisprudencia tradicional ha atribuido un ánimo de injuriar implícito, por ejemplo, a los actos de quema de la bandera española en público, en cambio, la doctrina que defiende la desaparición del delito de ultrajes a la bandera afirma su dudosa constitucionalidad al tratarse de un ilícito que carece de bien jurídico penal ${ }^{55}$ ya que para que un bien jurídico sea merecedor de tutela penal es necesario acreditar su importancia social

52 SOLOZABAL destaca que la nueva regulación rebaja la indeterminación del tipo y disminuye notablemente el castigo penal. Cfr. SOLOZABAL ECHEVARRÍA, J. J., «Comentario al art. 4», loc. cit. pág. 79.

53 Cfr. REBOLlO VARGAS, R, loc. cit. págs. 96-98. La Ley Orgánica 4/2015, de 30 de marzo, de protección de la seguridad ciudadana no contempla como infracción administrativa las ofensas o ultrajes a España, a las Comunidades Autónomas o las Entidades Locales, o a sus instituciones, símbolos o emblemas, efectuadas por cualquier medio, cuando no sean constitutivos de delito, que sí se contenía en el Anteproyecto de Ley.

${ }^{54}$ Cfr. SANTANA VEGA, D. M., «El delito de ultrajes a España y a sus Comunidades Autónomas: ¿Protege algún bien jurídico penal», Cuadernos de Política Criminal, núm. 99, 2009, págs. 35-66. TÉLlEZ AGUILERA, A., «Los ultrajes a España, visión crítica de un delito», Boletín del Ministerio de Justicia, núm. 1719, 1994, págs. 4796-4819.

55 Así, REBOLLO VARGAS discute si los sentimientos patrióticos o nacionales, extensibles a los símbolos que los representan, son merecedores de protección penal o incluso si las conductas o comportamientos que les afecten «tienen un contenido material de antijuridicidad idóneos como para ser merecedores de una protección penal» y subraya la vaguedad de un bien jurídico de estas características incompatible con el principio de legalidad —loc. cit. pág. 102_. 
como bien merecedor de protección, lo que no queda contrastado en este caso pues parte de la población se muestra indiferente a los símbolos oficiales de España. Evidentemente, la determinación en un Estado democrático de la importancia social de un bien jurídico como merecedor de protección penal le corresponde al legislador, que concreta el pluralismo político en este ámbito ${ }^{56}$, sin perjuicio de la crítica legítima por parte de la doctrina penalista. Por último, otra crítica al delito de ultrajes a España es que no es constitucionalmente aceptable la atribución de la titularidad del derecho al honor a un ente supraindividual, como es la nación, lo que obliga a considerar en este caso la vulneración del derecho al honor de los sujetos individuales que forman parte de esa colectividad ${ }^{57}$.

El principal cuestionamiento sobre el mantenimiento del delito de ultrajes a la bandera es que supone un límite a la libertad ideológica y a la libertad de expresión, que es un derecho preferente en conflicto con otros derechos fundamentales. El Tribunal Constitucional ha señalado que la dignidad y el prestigio de las instituciones presentan una protección más débil en relación con la libertad de expresión que el derecho al honor, que corresponde a las personas físicas. Es razonable que sea así porque la posibilidad de crítica a las instituciones forma parte del debate político y afecta a la existencia de una opinión pública libre en una sociedad democrática. Ahora bien, el prestigio y la dignidad de las instituciones también pueden merecer la protección penal que en su caso establezca el legislador. Además, el Tribunal Constitucional ha subrayado la posibilidad de lesionar el honor de las personas a través de ataques genéricos dirigidos a colectivos ${ }^{58}$. Pues bien, el art. $543 \mathrm{CP}$ tipifica como

${ }^{56}$ Hay que subrayar que la tipificación del delito de ultrajes a España se encuentra en el Código Penal de la democracia —en el llamado Código Belloch_-.

57 REBOLLO VARGAS analiza las dificultades que presenta una interpretación personalista del denominado honor nacional como bien jurídico protegido en estos delitos —loc. cit. pág. 101—. Así, no sería necesario el delito de ultrajes a España puesto que cada uno de los individuos podría denunciar la vulneración de su derecho al honor en tanto que miembros de esa colectividad, la nación.

58 Como recoge la STC 214/1991, de 11 de noviembre -F. J. 6. - - el derecho al honor «tiene en nuestra Constitución un significado personalista, en el sentido de que el honor es valor referible a personas individualmente consideradas, lo cual hace inadecuado hablar del honor de las instituciones públicas o de clases determinadas del Estado, respecto de las cuales, y sin negar que en algunos casos puedan ser titulares del derecho al honor (y así lo ha reconocido el TEDH, por ejemplo, con respecto al «Poder Judicial»: asunto Barfod, S. 22 de febrero de 1989), es más correcto desde el punto de vista constitucional emplear los términos de dignidad, prestigio y autoridad moral, que son valores que merecen la protección penal que les dispense el legislador, pero en su ponderación frente a la libertad de expresión debe asignárseles un nivel más débil de protección del que corresponde atribuir al derecho al honor de las personas físicas (SSTC 107/1988, 51/1989 y 121/1989)». Un ejemplo de que el prestigio de las instituciones también merece protección es la STC 177/2015, de 22 de julio, que más adelante analizamos. Sin embargo, la STC 214/1991, de 11 de noviembre, después de analizar el prestigio de las instituciones, aborda de manera inmediata la posibilidad de lesionar el honor de las personas a través de ataques genéricos dirigidos a colectivos. Como continua señalando la Sentencia, «lo anterior no ha de entenderse en sentido tan radical que sólo admita la existencia de lesión del derecho al honor constitucionalmente reconocido cuando se trate de ataques dirigidos a persona o personas concretas e identificadas, pues también es posible apreciar lesión del citado derecho fundamental en aquellos 
delito «las ofensas o ultrajes de palabra, o por escrito o de hecho a España, a sus Comunidades Autónomas o a sus símbolos o emblemas, efectuados con publicidad». Así, hay que reconocer recientemente el uso social de la bandera de España en los balcones — también de las esteladas- como lenguaje simbólico y, por tanto, como una manifestación de la libertad de expresión en el contexto de la declaración unilateral de independencia de Cataluña, que trasciende y va más allá del debate sobre la utilización y el protocolo de la bandera en edificios públicos. Sin embargo, el debate estriba en si otras conductas expresivas como la quema de la bandera de España o de las enseñas autonómicas también se encuentra amparada por la libertad de expresión o si el legislador tiene un margen de apreciación para proteger penalmente el prestigio de las instituciones a través de la protección de los símbolos. Hay que tener en cuenta, además, que estos actos pueden suponer, en ocasiones, un ataque o al menos una situación de desprotección a colectivos en algunas Comunidades Autónomas que exhiben la bandera de España como un elemento de integración en la comunidad nacional. Lógicamente, en este tipo de conductas hay que distinguir dos posibles delitos distintos: por un lado, el delito de ultraje a la bandera, cuando se ofende el prestigio de las instituciones - o el honor de las personas a través de ataques a colectivos-; y un delito de odio cuando lo que se trata es de una incitación a la violencia que genere un peligro de ataque o de desórdenes o sea un mensaje de contenido racista, supremacista o xenófobo que sea contrario a la dignidad de la persona.

El TEDH ha tenido en cuenta la doctrina sobre la libertad de expresión y el lenguaje simbólico del Tribunal Supremo de EE.UU, aunque, como reconoce el Magistrado del TEDH GARLICKI, sin el recurso al término symbolic speech ${ }^{59}$. El Tribunal Supremo de EEUU ha subrayado que las banderas son símbolos que tienen un significado pero que no tiene por qué ser el mismo para cada persona. El Estado no puede imponer ningún significado de manera oficial porque esto estaría en contradicción con el principio de neutralidad ideológica del Estado, que prohíbe el adoctrinamiento de los ciudadanos y con la Primera Enmienda de la Constitución Americana, que reconoce la libertad de expresión, teniendo en cuenta que las personas se pueden

supuestos en los que, aun tratándose de ataques referidos a un determinado colectivo de personas más o menos amplio, los mismos trascienden a sus miembros o componentes siempre y cuando éstos sean identificables, como individuos, dentro de la colectividad. Dicho con otros términos, el significado personalista que el derecho al honor tiene en la Constitución no impone que los ataques o lesiones al citado derecho fundamental, para que tengan protección constitucional, hayan de estar necesariamente perfecta y debidamente individualizados ad personam, pues, de ser así, ello supondría tanto como excluir radicalmente la protección del honor de la totalidad de las personas jurídicas, incluidas las de substrato personalista, y admitir, en todos los supuestos, la legitimidad constitucional de los ataques o intromisiones en el honor de personas, individualmente consideradas, por el mero hecho de que los mismos se realicen de forma innominada, genérica o imprecisa».

59 Cfr. CLIMENT GALLART, J., «La jurisprudencia estadounidense sobre el lenguaje simbólico en relación con las banderas y su acogimiento por el TEDH», REDF, núm. 28, 2016, págs. 303-328, esp. págs. 311-320; GARLICKI, L., «Symbolic speech», Freedom of expression. Essays in honour of Nicolas Bratza, President of the European Court of Human Rights, Wolf Legal Publishers, Oisterwijk, 2012. 
expresar no sólo de palabra — speech — sino también con conductas — conduct_- gestos o a través de símbolos —el lenguaje simbólico_- El Tribunal Supremo da mucha importancia a lo que se pretenda trasmitir con la simbología en la bandera, la llamada «conducta expresiva» —expressive conduct_ _ La Primera Enmienda no sólo protege las expresiones escritas u orales sino otras formas de expresión, siempre que transmitan un mensaje individualizado y que haya una probabilidad máxima de que sea entendido por los receptores, encontrándonos en ese caso ante una conducta expresiva, que debe ser analizada casuísticamente teniendo en cuenta el contexto en que se produce. Así, el Tribunal Supremo resolvió en Street v. New York (1969) que la quema de la bandera de EEUU está amparada por la Primera Enmienda al ser un ejemplo de discurso simbólico ${ }^{60}$. Posteriormente, en Texas v. Johnson (1989), el Tribunal Supremo señaló que «si existe un principio fundamental que subyace en la Primera Enmienda, es precisamente que el Gobierno no puede prohibir la expresión de una idea de por sí ofensiva o desagradable (...) No hemos reconocido una excepción a este principio, aun cuando esté en juego nuestra bandera (...) Hemos sostenido que no se puede sancionar por pronunciar palabras críticas a la bandera (...) Hemos extraído como conclusión que la libertad garantizada por la Constitución de ser intelectualmente distintos o aún contrarios, y el derecho a diferir en cuanto a las cosas que llegan al corazón del orden existente, abarca la libertad de expresar públicamente las opiniones propias acerca de nuestra bandera, incluyendo las opiniones que sean insolentes o despectivas (...) Hemos sostenido que tampoco puede el Gobierno imponer una conducta que demuestre respeto a la bandera» ${ }^{61}$. Finalmente, en U.S. v. Eichman (1990) el Tribunal Supremo de EEUU declaró la Ley de Protección a la bandera de 1989, impulsada por el Presidente Bush, contraria a la Primera Enmienda, basándose en la doctrina anterior ${ }^{62}$. Hay que resaltar que tanto Street v. New York (1969) como las posteriores Texas v. Johnson (1989) y U.S. v. Eichman (1990) fueron decisiones 5-4.

La doctrina del Tribunal Supremo de EEUU sobre el lenguaje simbólico ha tenido acogida por el TEDH y se ha aplicado a distintas manifestaciones de la libertad de expresión, no solo referida a las banderas ${ }^{63}$. Así, en la Sentencia de 2 de febrero de 2010 - Asunto Partido Demócrata Cristiano Popular contra Moldavia - , el TEDH resolvió amparando el derecho de reunión de unos manifestantes al mismo tiempo que señaló que la quema de banderas [de Rusia] era «una forma de expresar una opinión con respecto a un asunto de máximo interés público». En referencia a esta Sentencia, el Magistrado GAR-

${ }^{60}$ Cfr. GUNTHER, G. y SULLIVAN, K. M., Constitutional Law $13 .{ }^{\circ}$ ed., The Foundation Press, Westbury, New York, 1997, págs. 1219-1221.

${ }^{61}$ Cfr. GUNTHER, G. y SULLIVAN, K. M., op. cit. págs. 1221-1228. En esta Sentencia, el Juez KENNEDY, que había sido designado por los republicanos, conformó la posición mayoritaria, haciendo un voto concurrente. Quedaron en minoría los Jueces REHNQUIST, WHITE, O`CONNOR y STEVENS.

${ }^{62}$ Cfr. GUNTHER, G. y SULLIVAN, K. M., op. cit. págs. 1229-1230 —en esta Sentencia se produjo la misma composición de mayorías y minorías que en la Sentencia anterior-

${ }^{63}$ Cfr. CLIMENT GALLART, J., loc. cit. págs. 320-326. 
LICKI afirmó que la quema de banderas debe entenderse protegida por la libertad de expresión siempre que no haya violencia. En la STEDH de 24 de julio de 2012 - Asunto Faber contra Hungría - el Tribunal estableció que mostrar una bandera supone el ejercicio de la libertad de expresión aunque el Magistrado KELLER, en su voto discrepante, consideró que se debía haber aceptado la tesis del margen de apreciación nacional, señalando que esa bandera en el contexto en el que se exhibió podía enviar un mensaje racista y fascista y suponer un supuesto de abuso de derecho — art. $17 \mathrm{CEDH}$ -

En esta dirección, el Tribunal Supremo de EEUU ha establecido, especialmente a partir de Brandenburg $v$. Obio (1969), que no es suficiente para reputar como legítima la injerencia en la libertad de expresión que un discurso mostrara una intención o una aptitud genérica para producir daño - aunque fuera de manera remota - o que hipotéticamente se pudiera dar un peligro — «bad tendency»—, sino que es necesario que el peligro sea cierto e inminente — «clear and present danger» - ${ }^{64}$. Sin embargo, para TERUEL, cuando se trata de discursos provocadores a la violencia, el TEDH no ha recogido completamente esta doctrina americana que establece que para valorar si la injerencia es legítima haya que tener en cuenta conjuntamente la intención subjetiva de incitar y que el discurso sea idóneo para que se produzca de forma inminente la acción ilegal, porque el TEDH - y nuestro TC - considera suficiente para entender que existe incitación a la violencia un peligro potencial (no abstracto) ${ }^{65}$, además de reputarse ilegítimo el discurso de odio en tanto que tengan un contenido racista o xenófobo que sea contrario a la dignidad de la persona ${ }^{66}$. El TEDH, en la Sentencia de 15 de marzo de 2011 -Asunto Otegi

${ }^{64}$ Cfr. GUNTHER, G. y SUlLIVAN, K. M., Constitutional Law, cit. págs. 1040-1043. Cfr. BISBAL TORRES, M. «El mercado libre de las ideas de O. W. Holmes», REDC, núm. 81, 2007, págs. $183-208$.

${ }_{65}$ TERUEL analiza la evolución del clear and present danger en la jurisprudencia del Tribunal Supremo de EEUU y la compara con la jurisprudencia del TEDH que no ha dado una pauta clara en relación con el grado de peligrosidad necesario. Así, el TEDH «en la mayoría de [los casos en los que el Tribunal ha reconocido que había habido violación del Convenio] lo que ocurre es que, tras revisar el tenor y contexto del discurso, concluye que no hubo una auténtica incitación a la violencia. Además, para valorar la necesidad de la injerencia tiene en cuenta otros elementos como si se trató de un discurso de tipo político o que afecta al interés general o el tipo de sanción (su severidad o si se había tratado de una restricción preventiva). Por el contrario, cuando el TEDH percibe que a la luz del tenor y del contexto un discurso puede ser advertido como una forma de incitación a la violencia, aunque sea indirecta, entonces es generoso concediendo un amplio margen de apreciación a los países, según se ha dicho, y, en consecuencia, suele entender como necesarias las medidas que se hubieran adoptado». Cfr. TERUEL LOZANO, G., «Internet, incitación al terrorismo y libertad de expresión en el marco europeo», InDret núm 3, 2018, págs. 13-20 [Agradezco a este autor sus aclaraciones en este punto]. Cfr. más en general el análisis del conflicto entre la libertad de expresión y el derecho al honor en el TC y el TEDH en QUERALT JIMÉNEZ, A., La interpretación de los derechos: del Tribunal de Estrasburgo al Tribunal Constitucional, CEPC, Madrid, 2008, págs. 265-273; BUSTOS GISBERT, R., Los derechos de libre comunicación en una sociedad democrática (Art. 10 CEDH), en GARCÍA ROCA, J., y SANTOLAYA P., La Europa de los Derechos. El Convenio Europeo de Derechos Humanos, CEPC, Madrid, 2005, págs. 529-563.

66 STC 177/2015, de 22 de julio. Cfr. TERUEL LOZANO, G., «El discurso del odio como límite a la libertad de expresión en el marco del Convenio Europeo», ReDCE, núm. 27, 2017; id., «Discursos extremos y libertad de expresión: un análisis jurisprudencial», REJ, núm. 17/2017. 
Mondragón C. España- condenó a España por vulnerar el derecho a la libertad de expresión reconocida en el art. $10 \mathrm{CEDH}$, en este caso, no por el lenguaje simbólico sino por unas declaraciones realizadas por el portavoz de Sozialista Abertzaleak, sobre la Corona, institución que tiene también un importante contenido simbólico. En ellas se decía: "Cómo es posible que se fotografien hoy en día en Bilbao con el Rey español, cuando el Rey español es el jefe máximo del Ejército español, es decir, el responsable de los torturadores y que ampara la tortura y que impone su régimen monárquico a nuestro pueblo mediante la tortura y la violencia». El TEDH señaló que la libertad de expresión prevalece en este caso sobre las posibles injurias al Rey, porque este cuadro muy negativo del Rey como institución, que dan al relato una connotación hostil, no incita a la violencia ni supone un discurso del odio. Además, la naturaleza y la dureza de las penas impuestas — un año de prisión — son también elementos que deben tenerse en cuenta cuando se trata de medir la «proporcionalidad» de la injerencia, por lo que ésta no era necesaria en una sociedad democrática ${ }^{67}$.

${ }^{67}$ Recientemente la STEDH, de 13 de marzo de 2018 - Asunto Stern Taulats y Roura Capellera c. España-, ha declarado que España vulneró la libertad de pensamiento y la libertad de expresión - arts. 9 y $10 \mathrm{CEDH}$ - por una condena por un delito de injurias a la Corona a una pena de quince meses de prisión e inhabilitación de sufragio pasivo durante ese tiempo, en relación con la quema, previa colocación hacia abajo, de una fotografía de los Reyes, durante una visita oficial de estos a Girona y que se desarrolló durante una concentración bajo el lema «300 años de borbones, 300 años combatiendo la ocupación española». Con anterioridad, el Tribunal Constitucional en la Sentencia 177/2015, de 22 de julio, había afirmado que la quema de la fotografía era un acto propio de una intolerancia excluyente y una vertiente derivada del discurso de odio. Para el Tribunal Constitucional, la escenificación de los hechos traslada a quien lo visiona la idea de que los Monarcas merecen ser ajusticiados. Para el Tribunal Constitucional estos hechos no eran inocuos para la seguridad y la dignidad de las personas y existía una incitación a la violencia y unos actos de amenaza que no respetaban la libertad de los demás ni contribuían a la formación de una opinión pública libre -F. J. 4. ${ }^{\circ}$ y $15 .^{\circ}-$. Sin embargo, como ponen de manifiesto los votos particulares, la incitación al odio no encaja en el delito de injurias a la Corona. En todo caso, hay que enjuiciar la conducta en el contexto de nuestro país, donde muchas personas han sufrido un fenómeno de violencia larvada, se han visto amenazadas y han vivido durante años un problema de libertad, especialmente de libertad de expresión. Es en ese contexto nacional donde debe valorarse la conducta de la quema de la fotografía de los Reyes, durante su visita a Girona y si ese acto es inicuo o puede ser visto como una amenaza para la libertad y la seguridad de las personas que viven en Comunidades Autónomas con gobiernos nacionalistas y que quieren mostrar su apoyo al Rey, símbolo de la unidad y permanencia del Estado; es decir, hay que valorar si se trata únicamente de un acto de hostilidad hacia los Reyes de visita oficial ese día en Girona o hacia un sector de la población que recibe a los Reyes y que puede quedar finalmente amedrentado para no dar este apoyo popular. La condena penal no se fundamentó en la posición ideológica de los recurrentes ni en su ejercicio legítimo de la libertad de expresión manifestado a través de una crítica dura a la institución de la monarquía. Nadie impidió la concentración y los lemas ahí repetidos que sí estaban amparados por la libertad ideológica y la libertad de expresión, por lo que no puede afirmarse que la condena por la quema de la fotografía de los Reyes desaliente por su severidad, suponga un sacrificio innecesario o desproporcionado de la libertad o tenga un efecto disuasorio o desalentador del ejercicio de los derechos fundamentales implicados en la conducta sancionada. No se trata de proteger a la monarquía sino de proteger la libertad de las personas que en determinadas Comunidades Autónomas viven amilanadas y sometidas al rechazo y a la exclusión política, evitando con la condena enviarles un mensaje de desprotección que en este caso sí disuade del ejercicio de la libertad de expresión. También es necesario analizar si para mostrar un 
Esta jurisprudencia del TEDH favorece el planteamiento de que el «delito de ultraje a la bandera» debería de ser suprimido del Código Penal ${ }^{68}$. Para esta doctrina, aunque la expresión suponga un ataque al «corazón del orden» o sea insolente o despectiva con España o con sus símbolos, la libertad de expresión es un derecho preferente y no debe limitarse salvo que impida el ejercicio de los demás derechos o suponga una incitación a la violencia de manera real y efectiva, no meramente hipotética. Sin embargo, también es necesario valorar si en este punto cabe un margen de apreciación nacional ${ }^{69}$. Hay que recordar que el TEDH no siempre ha seguido la doctrina protectora de la libertad de expresión del Tribunal Supremo Norteamericano. Así, ha afirmado que el discurso negacionista o revisionista del holocausto judío no se encuentra protegido por el art. $10 \mathrm{CEDH}$ mientras que el Tribunal Supremo sí lo ha considerado amparado por la Primera Enmienda, abriéndose la puerta a un margen de apreciación nacional en este ámbito. Si el TEDH ha tenido en cuenta en este punto la realidad histórica europea, que ha sufrido directamente los horrores del nazismo y que es distinta a la de EEUU, también es necesario valorar la realidad histórica española marcada durante años recientes por la violencia terrorista en relación con la integridad territorial o por un conflicto bélico nacional a la hora enjuiciar la legitimidad del Parlamento para proteger los símbolos nacionales ${ }^{70}$. Hay que recordar también que la protección de la bandera

juicio crítico hacia la monarquía es necesario quemar la fotografía de los Reyes, si esto contribuye en algo mínimo a una opinión púbica libre, si esta injerencia supera el juicio de necesidad y, en definitiva, si las conductas expresivas están exentas de respetar el principio de proporcionalidad.

68 Esta es la posición que mantiene la doctrina penalista antes citada.

69 Cfr. desde una perspectiva crítica GARCÍA ROCA, J., El margen de apreciación nacional en la interpretación del CEDH: soberanía e integración, Civitas-Thomson Reuters, Cizur Menor, 2010, págs. 131-188.

70 TERUEL ha puesto de manifiesto también la posición distinta del Tribunal Supremo de EEUU y del TEDH en relación con los límites a la libertad de expresión ante discursos que incitan al terrorismo. Así, señala que «en Europa se puede observar una inclinación favorable a justificar este género de limitaciones [mientras] que en los EE.UU. se ha seguido una aproximación indirecta para evitar la confrontación con la Primera Enmienda norteamericana» — loc. cit. pág. 14_. Afirma este autor que «la intensidad del control que realiza el TEDH o, si se prefiere, el margen de apreciación que concede a los Estados, se ve modulado por distintos factores. Así, por ejemplo, cuando se trata de un discurso político o de materias cuyo debate resulta de interés general el control será más intenso, mientras que si está en juego la seguridad nacional ante conductas incitadoras a la violencia en contextos conflictivos permitirá un mayor margen de apreciación». De hecho, «la seguridad nacional e incluso la integridad territorial han sido admitidas por el Tribunal Europeo como fines legítimos para justificar la represión de actos incitadores de la violencia terrorista cuando se producen en contexto conflictivos» -loc. cit. págs. 15-16- Así, por ejemplo, en la Sentencia de 2 de octubre de 2008 - Asunto Leroy c. Francia-, el TEDH entendió necesaria la sanción a un texto satírico por el delito de apología del terrorismo porque podía provocar violencia y tener un impacto plausible en el orden público de la región vasca. También el TEDH reconoció el margen de apreciación a favor de Alemania en la Decisión de 20 de enero de 2000 -Asunto Hogefeld c. Alemania_-, a raíz de unas declaraciones de una antigua miembro de una organización terrorista las cuales habían sido consideradas por los tribunales alemanes como promoción o apoyo del terrorismo. 
como símbolo de la nación tiene su correspondencia con la inviolabilidad del Rey — art. 56.3 CE—, otro símbolo del Estado, y la de la las Cortes Generales que representan al pueblo español —art. $66 \mathrm{CE}$ — . Desde esta posición se puede mantener, como ha hecho la jurisprudencia española ${ }^{71}$, que, si bien la manifestación de ideas independentistas o contrarias a la unidad de España, incluso cuando fueran despectivas, vulgares o críticas estarían protegidas por la libertad de expresión si no van acompañadas de actos violentos, al mismo tiempo, el acto de la quema de la bandera de España no supone un ejercicio legítimo de la libertad de expresión sino un abuso de este derecho y representa una conducta tipificada en el delito de ultraje a España o sus símbolos previsto en el art. 543 del Código Penal, querido expresamente por el legislador. El reconocimiento constitucional de las banderas y enseñas de España y de las CCAA significa que son un bien constitucional, lo que conlleva, como señala SolOZABAL, «su protección jurídica» ${ }^{72}$, con independencia de que exista o no una incitación al desorden público o la comisión otro delito, lo que justifica el mantenimiento de este tipo penal que no ha sido cuestionado hasta ahora por la jurisprudencia constitucional.

c) La prohibición de la exhibición en edificios públicos de banderas partidistas y de la utilización partidista de la bandera de España

La bandera, como hemos subrayado antes, es un símbolo de integración y refleja los valores constitucionales recogidos en el art. 1.2 CE, también el pluralismo político. Por ello, la Administración Pública, como manifestación de que sirve con objetividad los intereses generales —y no a los intereses particulares o de partido-, actúa con sometimiento pleno a la ley y al Derecho y está servida por funcionarios públicos que ejercen sus funciones con imparcialidad — art. 103.3 CE— sólo puede exhibir en sus edificios la bandera de España y las banderas y enseñas propias de las CCAA y no banderas partidistas. Hay que destacar en este sentido la STSJ CL 5043/2015, de 29 de octubre que condena al Ayuntamiento de Miranda de Ebro por la pasividad ante el requerimiento de retirar una bandera republicana de un balcón trasero del Ayuntamiento, que se corresponde con el despacho de un concejal, recordando que la norma es taxativa a la hora de mencionar qué banderas deben ondear en determinados edificios públicos como muestra del principio de neutra-

71 Cfr. el estudio jurisprudencial realizado por REBOLLO VARGAS, R., loc. cit. págs. 111-126.

72 No obstante, para este autor, «el cuestionamiento de la protección penal de los símbolos políticos, no obstante el reconocimiento constitucional de los mismos, es una opción razonable y, por tanto, opinable, que naturalmente la jurisprudencia constitucional no se plantea». Cfr. SOLOZABAL ECHEVARRÍA, J. J., «Comentario al art. 4», loc. cit. pág. 78. GARRORENA MORALES, A considera que el art. 4.2 CE contiene un principio de constitucionalidad de las banderas autonómicas, que disponen de un status constitucional, con las consecuencias que esto tiene en orden a su intangibilidad y a su defensa por medios jurídicos —loc. cit. pág. 1025-. 
lidad política que debe presidir la actuación de la Administración pública, dejando claro que en ningún momento se limita el derecho de libertad de expresión del concejal ni del partido político, ya que estos tienen todo el derecho de hacer uso de esa libertad, en la sede de su partido o en sus dependencias particulares, pero no cuando se trate del Ayuntamiento porque a la imagen exterior de los edificios públicos les es inherente y les resulta indisociable su sentido de organización institucional del Estado que no puede ser «arbitrada en cada momento y ocasión por quienes ejercen las potestades que les caracterizan, por más que provengan del sufragio o elección popular» ${ }^{73}$.

Recientemente, la STS 1841/2016, de 28 de abril, en relación con un Acuerdo de la Junta Electoral Central que ordenaba la retirada de las banderas «esteladas» de los edificios públicos y locales electorales durante el período electoral, señaló: por una parte, que lo relevante no es que la bandera estelada pertenezca o no a un partido sino que no pertenece y no se identifica con la comunidad de ciudadanos que en su conjunto, con independencia de mayorías o minorías, constituye jurídicamente el referente territorial de cualquiera de las Administraciones, siendo notorio que es un símbolo de la reivindicación independentista de una parte de los ciudadanos catalanes $^{74}$; por otra parte, la vinculación entre democracia y Estado de derecho por lo que el hecho de que la colocación de las banderas esteladas sea por acuerdos de órganos colegiados tomados democráticamente y donde se plasma la voluntad del pueblo no los hace en modo alguno conformes a derecho, recordando que las instituciones públicas, a diferencia de los ciudadanos, no tienen libertad de expresión; por último, que la actividad partidista era incompatible con el deber de

73 F. J. 5. ${ }^{\circ}$, citando la STJ PV 415/2014, de 29 de septiembre. La STSJ M 16861/2003, de 15 de diciembre consideró acertadamente que la Resolución del Alcalde del Ayuntamiento de Torrelodones, que ordenaba a la demandante la retirada de la bandera tricolor republicana del chiringuito de Izquierda Unida donde ondeaba en las fiestas patronales por generar eventualmente alguna situación de riesgo y de alteración del orden públicos supone una vulneración de la libertad de expresión: «Por si misma dicha bandera difícilmente puede incitar a la violencia, el racismo, la xenofobia o cualquier otra forma de discriminación que atente contra la dignidad humana, prohibiciones éstas que eran las únicas que se imponían al otorgar la concesión de la instalación de establecimientos destinados a puestos de bebidas en fiestas patronales» —-F. J. 5. ${ }^{\circ}$ -

${ }^{74}$ Como señala V. J. VÁZZUEZ, la ubicación de una estelada en un espacio público por parte del Ayuntamiento de Sant Cugat del Valle «es un presupuesto para que los ciudadanos que no se identifican con el mismo tengan la percepción de que son outsiders o integrantes de segunda categoría dentro de la comunidad política a la que pertenecen [...]. Por decirlo de una forma clara: en este contexto institucional, el reconocimiento tiene siempre un envés que es, en mayor o menor grado, la sensación de exclusión —o de desprecio— de los no reconocidos». De esta forma, «la participación política en contextos de plena confusión o solapamiento simbólico entre las instituciones de gobierno y una opción ideológica se asemeja mucho a una simulación democrática». Cfr. VÁZQUEZ, V. J., «Neutralidad y legitimidad de las instituciones en Cataluña», Agenda Pública, 30 de julio de 2018. Sobre la neutralidad política de las instituciones públicas y el concepto de government speech del Tribunal Supremo de EEUU, cfr. VÁZQUEZ, V. J., «La neutralidad del Estado y el problema del government speech», REP, núm. 17, 2017, págs. 13-55.

N. ${ }^{\circ} 103$, septiembre-diciembre 2018, págs 29-76 
objetividad y neutralidad de la Administración Pública, algo esencial, además, para garantizar el sufragio igualitario ${ }^{75}$.

La bandera de España no tiene carácter partidista por lo que no es admisible una utilización de la misma como símbolo oficial de un partido político, de manera que se traslade a la sociedad la idea de que la bandera es patrimonio de una parte de la población. Si bien es legítima la exhibición de la bandera española por los partidos políticos también en sus actos electorales, la legislación contiene dos prohibiciones concretas que evita que la bandera se identifique con un grupo político y alcance ese carácter partidista. La primera es la prohibición de «utilización en la bandera de España de cualesquiera símbolos o siglas de partidos políticos, sindicatos, asociaciones o entidades privadas — art. 8 de la Ley 39/1981, de 28 de octubre_- La segunda es que no pueden presentarse candidaturas a las elecciones «con símbolos que reproduzcan la bandera o el escudo de España, o con denominaciones o símbolos que hagan referencia a la corona» —art. 46.5 LOREG_- Recientemente, la STS 841/2017, de 1 de marzo, declaró no ajustado a derecho el Acuerdo de la Junta Electoral Central que impedía los envíos postales de propaganda electoral del VOX en la que aparecía la bandera de España y su escudo por vulnerar los preceptos mencionados y por inducir a confusión con los envíos oficiales o institucionales. El TS subrayó, como también señalaba el Ministerio Fiscal, que el nombre o el signo del partido político no aparecía en la bandera española de los sobres y que la bandera tampoco aparecía en la candidatura de Vox sino en el «buzoneo electoral». Por tanto, esta propaganda electoral no vulneraba ningún precepto legal, teniendo en cuenta, además, que las normas prohibitivas deben ser interpretadas de manera restrictiva por lo que la Sentencia concluyó que el Acuerdo de la Junta Electoral Central había vulnerado el derecho a la participación política —art. 23 CE—, aunque sin hacer una referencia explícita a la libertad ideológica y de expresión que sí se encontraban mencionadas en la demanda.

d) Los conflictos por la utilización de las banderas de las Comunidades Autónomas.

También la utilización de las banderas de las Comunidades Autónomas ha dado lugar a conflictos. Como ya hemos señalado, el art. 4.2 CE establece que «los Estatutos podrán reconocer banderas y enseñas propias de las Comunidades Autóno-

75 Cfr. también el Acuerdo de la Junta Electoral Central, de 4 de diciembre de 2017, en relación con la colocación de símbolos que pudieran considerarse partidistas en edificios públicos y lugares de titularidad pública. Recientemente el Acuerdo de la Junta Electoral de Zona de Barcelona, de 15 de diciembre de 2017, había acordado retirar las banderas españolas y catalanas del despacho de Ciudadanos en el Ayuntamiento de Santa Coloma de Gramenet — que se apreciaban desde la calle — afirmando que representaban el símbolo que había usado ciudadanos para identificarse en los últimos hechos acontecidos en Cataluña con el proceso independentista y también en la campaña electoral de las elecciones del 21 de diciembre de 2017. Posteriormente el Acuerdo de la Junta Electoral Provincial de Barcelona, de 18 de diciembre de 2017, revocó el Acuerdo anterior, señalando que «las bandera o símbolos oficiales no son de carácter partidista, siendo su colocación y uso de carácter neutral desde un punto de vista político». 
mas». La STC 94/1985, de 29 de julio, define el art. 4.2 CE como una norma de atribución de competencias y como un específico título competencial externo a las reglas contenidas en los arts. 148 y $149 \mathrm{CE}^{76}$. Como acertadamente señala SolozaBAL, el art. 4.2 CE contiene una reserva de estatuto que atribuye al Estatuto de autonomía la exclusiva competencia para el reconocimiento de banderas y enseñas propias y que tiene un «sentido habilitador» porque habilita al legislador estatutario, que sin esta previsión concreta no podría intervenir. De esta forma, las competencias asumidas por las CCAA no se deducen únicamente de las cláusulas competenciales específicas — arts. 148 y 149 CE — sino también de cláusulas como el art. 4.2 CE que contienen reservas estatutarias ${ }^{77}$. Esta Sentencia resuelve el conflicto constitucional de competencia promovido por la Diputación Foral de Navarra que solicitaba la competencia exclusiva para disponer sobre el uso de su escudo de armas, frente al Acuerdo del Consejo General del País Vasco, de 2 de noviembre de 1978, que adoptó su escudo — Laurak-Bat_, integrando también el escudo de armas de Navarra, alegando que «el derecho a utilizar cadenas [en su escudo] no es algo exclusivo de Navarra», y que se había introducido con la previsión de la entrada de Navarra en el País Vasco. El Tribunal Constitución señaló que la función identificadora del símbolo político determina que el contenido competencial del art. 4.2 CE no se agota «en la potestad para fijar las características de sus propios símbolos sino que abar[ca] también —ya que de otro modo la relación de identidad quedaría rota - la potestad frente a las demás Comunidades para regular de forma exclusiva su utilización». Ello implica que «dichos símbolos no pueden ser utilizados sin el consentimiento de la Comunidad a que corresponden, ni apropiándose de ellos aisladamente, ni integrándolos como tales símbolos identificadores en el emblema de otra Comunidad. El contenido de la competencia así definida supone, por consiguiente, un límite a la competencia de cada Comunidad Autónoma para establecer o configurar su propio emblema» ${ }^{78}$.

En esta dirección hay que subrayar asimismo la SJCA de Pamplona 84/2016, de 1 de marzo, en relación con la denuncia de que ondeara en el exterior del Ayuntamiento de Pamplona la bandera del País Vasco durante el chupinazo de las fiestas de San Fermín. La Sala, teniendo en cuenta una STSJ NA 335/2013 de 28 de noviembre que ya analizó la existencia de vías de hecho para la exhibición en Ayuntamientos de banderas ajenas a la Comunidad Foral de Navarra, subrayó que la previsión de la Ley

${ }^{76}$ F. J. 8. ${ }^{\circ}$.

77 Cfr. SOLOZABAL ECHEVARRÍA, J.J., «Comentario al art. 4», loc. cit. págs. 77-78.

78 Sin embargo, RUBIO LLORENTE y DÍEZ-PICAZO en su voto particular discrepante niegan el carácter competencial del art. 4.2 CE y que esta supuesta competencia se extienda al derecho de propiedad sobre un símbolo y a la facultad de un uso exclusivo frente a las demás Comunidades Autónomas. GARRORENA MORALES, A, discrepa del elemento de exclusividad porque dos Comunidades Autónomas pueden tener un pasado común y pueden compartir símbolos pertenecientes a la historia de ambas _loc. cit. pág. 1026-1027_. 
Foral 24/2003, de 4 de abril, de Símbolos de Navarra, que permite extraordinariamente la presencia de banderas de otras CC.AA. exclusivamente como acto de cortesía con autoridades en visita oficial no se correspondía con el supuesto de hecho en este caso donde se había producido un fraude de ley — no se había colocado la bandera del País Vasco porque hubieran acudido personalidades sino porque se les había invitado «para dar cobertura a un acto que, sin ellas, sería contrario a derecho»— ${ }^{79}$. Hay que tener en cuenta la Exposición de Motivos de la Ley Foral de Símbolos donde se recoge que «cuando un pueblo tan consistente históricamente como el navarro se ve, aunque sea en mínima medida, afectado por el rechazo o la descalificación para mantenerse con firmeza como Comunidad singular, propia y diferenciada, ve sus símbolos como auténtica representación comunitaria y no puede consentir que se vean menoscabados por la intolerancia de quienes pretenden imponer otros símbolos, de otras identidades contrapuestas, que puedan pretender dar carácter oficial a lo que, en todo caso, sólo es una fórmula de alternativa comunitaria posible y no probable.»

\section{LA CAPITALIDAD}

\section{El concepto constitucional de capitalidad: la sede de las instituciones generales del Estado}

La capitalidad está en los orígenes de un Estado y tiene más fuerza en los Estados centralizados que en los fuertemente descentralizados. La capitalidad no sería en puridad un símbolo aunque también tiene un importante componente simbólico. De hecho, una de las primeras decisiones que se adoptó después de la unificación alemana fue el traslado de la capitalidad de Bonn a Berlín. En esta dirección, STERN analiza la capitalidad dentro de los símbolos del Estado de la República Federal de Alemania ${ }^{80}$. Como señala ViLLAVERDE «aunque en puridad los símbolos del Estado se regulan en el art. 4 CE, es innegable la función simbólica de la identificación de la capital del Estado» ${ }^{81}$. En esa misma dirección, para LuCAS VERdú, la definición de la capitalidad en el Título Preliminar es significativa porque este título contiene la fórmula política de la Constitución y expresa la Constitución en sentido material» ${ }^{82}$. VILLAVERDE señala que la redacción del art. 5 CE deja al intérprete perplejo, pues «o bien apenas dice sólo lo que dice»o «en su simpleza lo contiene todo, un modelo de forma de Estado y de Gobierno». Para este autor «no es baladí que la capital lo sea del Estado y no del Reino de España» ${ }^{83}$.

79 F. J. 5. .

80 Cfr. STERN, K., op. cit, págs. 515-516.

${ }^{81}$ Cfr. VILLAVERDE MENÉNDEZ, I., «Comentario al art. 5», en CASAS M. E. y RODRÍGUEZ PIÑERO, M., Comentarios a la Constitución Española, XXX Aniversario, Fundación Wolters Kluwer, Madrid, 2009, pág. 81.

${ }^{82}$ Cfr. LUCAS VERDÚ, P. «Artículo 5.․ La capitalidad», en ALZAGA VILLAAMIL, O. (Dir.), Comentarios a la Constitución Española de 1978, cit. pág. 299.

83 Cfr. VILLAVERDE MENÉNDEZ, I., loc. cit. págs. 80-81. LUCAS VERDÚ entiende que el constituyente evitó replicar al art. 5 de la Constitución de 1931 —ibidem pág. 299—. 
La atribución a Madrid de la capitalidad del Estado recogida en el art. 5 CE tiene como antecedente en nuestra historia constitucional el art. 5 de la Constitución de 1931 que señalaba que «la capitalidad de la República se fija en Madrid». En el Derecho Constitucional Comparado hay que mencionar la Constitución Alemana que señala que «la Capital de la República Federal de Alemania es Berlín» — art. 22.1—. Con anterioridad a la aprobación de nuestra Constitución, la Constitución de Bélgica recogía que «la villa de Bruselas es la capital de Bélgica» — art. 194 - y la Constitución de Italia establecía que «Roma es la capital de la República» —art. 114_ ${ }^{84}$. Esta referencia constitucional a la capitalidad es especialmente apreciable en países que han aprobado sus Constituciones recientemente después de procesos de transformación política o de configuración nacional ${ }^{85}$ pues la idea de ciudad-capital «constituye una pieza fundamental en el proceso simbólico de afirmación de la independencia» ${ }^{86}$. Hay otros países que no recogen en su Constitución un establecimiento de la capitalidad -Francia, Portugal, Grecia, Dinamarca, Suiza, Finlandia, Suecia, Malta, Estonia-.

La decisión de fijar la capital de España en Madrid no fue una cuestión polémica en el proceso constituyente, a diferencia del debate sobre la determinación de la capitalidad que sí se produjo durante el periodo estatuyente en Comunidades Autónomas como Galicia, Extremadura o Canarias. Hay que mencionar en el debate constituyente la intervención de Camilo José Cela en el Senado que defendió que el artículo se limitara a señalar que la capital de España es Madrid y no la villa de Madrid, justificándolo tanto en que «es lo que nos decían en el colegio como en que desde que es Obispado, probablemente es ya, en todo caso, ciudad» ${ }^{87}$.

${ }^{84}$ Otras menciones semejantes a la capitalidad se encuentran en el art. 108 de la Constitución de Austria, en el art. 32 de la Constitución de los Países Bajos y en el art. 109 de la Constitución de Luxemburgo.

85 Art. 29 de la Constitución de Polonia, art. F de la Constitución de Hungría, art. 13 de la Constitución de la República Checa, art. 10 de la Constitución de Eslovaquia, art. 169 de la Constitución de Bulgaria, art. 14 de la Constitución de Rumanía, art. 17 de la Constitución de Lituania, art. 13 de la Constitución de Croacia y art. 10 de la Constitución de Eslovenia.

${ }^{86}$ Cfr. SANTAMARÍA PASTOR, J. A. «Capital del Estado», en Enciclopedia Jurídica Básica, Civitas, Madrid, 1995, I, pág. 916.

${ }^{87}$ Cfr. ALZAGA VILLAAMIL, O., Comentario sistemático a la Constitución de 1978, cit. págs. 95-96; ENTRENA CUESTA, R., «Artículo 5», en GARRIDO FALLA, F., Comentario a la Constitución, cit. págs. 88-90; LUCAS VERDÚ, P. «Artículo 5.․ La capitalidad», cit. págs. 297-300; VILLAVERDE MENÉNDEZ, I., «Comentario al art. 5», cit. págs. 80-82; PIÑAR MAÑAS, J. L., «El régimen de capitalidad del Estado», AA.VV., Madrid. Comunidad Autónoma Metropolitana, IEE, Madrid, 1983; AVEZUELA CÁRCEL, J. «Madrid, capital del Estado», en ÁLVAREZ CONDE, E., El Derecho Público de la Comunidad de Madrid, CEURA-Universidad Rey Juan Carlos, Madrid, 2003, págs. 196-2011. He tenido la oportunidad de ocuparme de esta cuestión con más amplitud en el «Preámbulo», en TRONCOSO REIGADA, A. (Dir.), Comentarios a la Ley de Capitalidad y de Régimen Especial de Madrid, Thomson-Aranzadi, 2006, págs. 57-199, del que provienen algunos de los planteamientos presentes que se mencionan en este texto. Quiero advertir expresamente que en este texto se recogen resumidos algunos párrafos de ese primer trabajo, cuya extensión - 142 págs. — lo hacía tal vez menos accesible y comprensible, y que por ello ahora retomo. Cfr. también en ese libro, entre otros, los trabajos de ARANDA ÁLVAREZ, E., FERNÁNDEZ MIRANDA, J; GARCÍA FERNÁNDEZ, J.; MEDINA GUERRERO, M., SERRANO ANTÓN, F. y RUIZ RICO, G.

N. ${ }^{\circ} 103$, septiembre-diciembre 2018, págs 29-76 
El art. 5 CE tiene un contenido definido y delimitado pues se trata de un precepto constitucional con una clara densidad normativa. Así, este artículo contiene una cláusula cerrada, no una cláusula abierta, lo que reduce la libertad del legislador y el margen de interpretación por parte del Tribunal Constitucional. El constituyente ha fijado con claridad que Madrid y no otra ciudad es la capital del Estado. Al incluirse este artículo dentro del Título Preliminar, una eventual modificación de la capitalidad - por ejemplo, para fijar una capital compartida — requeriría una reforma constitucional mediante el procedimiento agravado previsto en el art. $168 \mathrm{CE}^{88}$. La atribución a Madrid de la capitalidad no es una proclamación retórica sino que tiene un contenido jurídico que es indisponible para el legislador. La capitalidad, en primer lugar, hace referencia a un lugar fijo desde donde se ejerce la soberanía. Por ello, el Rey, como Jefe del Estado — que tiene atribuida la representación del Estado en su conjunto; manifiesta el consentimiento del Estado para obligarse en el ámbito internacional; perfecciona, finaliza y formaliza los actos de otros poderes del Estado; dispone del poder de legación activa y pasiva (art. $63 \mathrm{CE}$ ); y simboliza la unidad y permanencia del Estado (art. 56.1 CE)—- debe tener su residencia en la capital ${ }^{89}$. Así, históricamente la capital era la sede del poder real ${ }^{90}$. En segundo lugar, la capitalidad hace referencia a la representación del Estado. Durante la Edad Contemporánea, la construcción del Estado como persona jurídica necesitó inevitablemente un domicilio conocido a todos los efectos tanto en las relaciones internas como en las internacionales ${ }^{91}$. Atribuir a una ciudad la capitalidad significa convertirla en cabeza — capitaspolítica visible de un territorio, sea Estado, Comunidad Autónoma o Provincia. La capitalidad a la que hace mención el art. 5 CE es la del Estado, lo que atribuye a esta ciudad una posición central dentro del Estado. La Constitución de Alemania al regular la capitalidad de la República Federal también hace referencia a este concepto de

88 Para ALZAGA, en cambio, el silencio de las Constituciones extranjeras sobre la capitalidad se explica «por la conveniencia de conservar un margen de flexibilidad para poder cambiar la capitalidad». Cfr. AlZAGA VILlAAMIL, O., Comentario, cit. pág. 95.

89 La Constitución de los Países Bajos cita la capital Ámsterdam como el lugar donde se tomará al Rey juramento, una vez haya asumido la ejecución de las funciones regias, y se le entronizará en sesión pública y conjunta de los Estados Generales — art. 32-, aunque La Haya sea la capital administrativa y efectiva del Reino.

90 Igualmente en las formas de gobierno republicanas la Presidencia de la República tiene su sede en la capital.

91 Cfr. ARAGÓN REYES, M., «El estatuto de capitalidad de Madrid», en AGUIAR DE LUQUE L. et al., Constitución, Estado de las autonomías y justicia constitucional, Libro bomenaje al profesor Gumersindo Trujillo, Tirant lo Blanch, Valencia, 2005, págs. 901-913, esp. pág. 902 [citaré este trabajo al ser el último]. Cfr. también de este autor con anterioridad «El significado jurídico de la Capitalidad», en REDC, núm. 50, 1997, págs. 127-140; id. «El Estatuto de Capitalidad de Madrid», en Cuadernos de Derecho Local núm. 3, 2003, págs. 21-26. Para VILLAVERDE, la definición jurídica de capitalidad cumple la función de «ser símbolo espacial del lugar desde el que se ejerce la soberanía en un Estado» - de ahí la relevancia en el Derecho internacional de identificar las capitales en las relaciones entre Estados_-, lo que requiere que la capital sea una sede fija — loc. cit. pág. pág. 81—. 
representación cuando señala que «la representación de la totalidad del Estado en la capital federal incumbe a la Federación» —art. 22.1—.

En esta dirección, ARAgón ha recogido la opinión de Livio PALAdin para quien en la capital del Estado no tienen por qué tener su sede las más altas instituciones del Estado sino al menos una de ellas, la Jefatura del Estado o el Poder Ejecutivo ${ }^{92}$. ArAGÓN ha distinguido en relación con el principio jurídico de capitalidad entre un contenido propio o amplio de capitalidad — que exigiría que todas las instituciones políticas tengan su residencia en ella - y un contenido mínimo - que admitiría que sólo la Jefatura del Estado tuviera la sede en ella-. Entiende que el contenido propio supone aceptar la existencia de una reserva de Constitución para la fijación de la sede de los órganos supremos del Estado, de manera que sólo pueden residenciarse fuera si la Constitución lo hubiera previsto. Aragón se inclina por el contenido mínimo, entendiendo que cuando la Constitución guarda silencio, puede hablar el legislador — sólo él, no el Gobierno ni siquiera los demás órganos constitucionales-. Así, muchos autores han mantenido una interpretación estricta del art. 5 CE que atribuya un contenido mínimo - no amplio — a este precepto y que deja una amplia libertad al legislador para que lo desarrolle políticamente. Esta libertad del legislador afectaría especialmente al establecimiento de la sede de las instituciones generales del Estado. Desde esta posición, la capitalidad no implica la sede de los poderes del Estado y de los órganos constitucionales sino sólo de uno de ellos, la Jefatura del Estado.

Sin embargo, una noción generalmente admitida de la capitalidad también conlleva ser la sede de los órganos de poder del Estado, es decir, del Poder Legislativo - Congreso de los Diputados y Senado_- del Poder Ejecutivo — Gobierno-y del Poder Judicial — Tribunal Supremo-, del Ministerio Fiscal-y de los órganos constitucionales - Tribunal Constitucional $^{93}$, Consejo General del Poder Judicial, Defensor del Pueblo, Tribunal de Cuentas, Consejo de Estado-. En esta dirección, la Constitución de Bélgica establece que la capital es «la sede del Gobierno Federal» —art. 194-. Igualmente la Constitución de Luxemburgo señala que la villa de Luxemburgo es «la capital del Gran Ducado de Luxemburgo y la sede del Gobierno. No se podrá trasladar la sede del Gobierno sino momentáneamente y por razones graves» — art. 109_. La Constitución de Chipre, aunque no alude a ninguna ciudad como capital, establece que el Tribunal Constitucional — art. 133.2 - y el Tribunal Supremo — art. 153.2 — han de ubicarse en la capital de la República.

92 Cfr. ARAGÓN REYES, M, loc. cit. págs. 902-907.

93 Es interesante mencionar en este sentido el Auto del Tribunal Constitucional 236/1984, de 11 de abril, en relación con la posibilidad de presentar escritos de interposición de los recursos de amparo en cualquier Juzgado de Guardia existente en el territorio nacional, donde se señala lo siguiente: «Tampoco puede admitirse la tesis [...] con el simple argumento de que una interpretación distinta supondría discriminación respecto de los españoles que vivimos fuera de Madrid (sic), pues la discriminación se encuentra establecida en el caso de que, se la quiera llamar así, por el art. 5 de la Constitución que coloca en la Villa de Madrid la capital del Estado». 
Así, considerar que la noción de capitalidad no implica ser sede de las instituciones generales del Estado supone vaciar de contenido el precepto constitucional. Una interpretación flexible que no vacíe de contenido constitucional la noción de capitalidad y que al mismo tiempo permita un margen de maniobra al legislador podría consistir en que los órganos de poder del Estado y los órganos constitucionales tengan su sede en Madrid, si bien la existencia de alguna excepción no vulneraría el precepto constitucional ${ }^{94}$ y no requeriría una reforma constitucional por el procedimiento agravado. El establecimiento de los órganos de poder del Estado y de las instituciones generales fuera de Madrid como regla — no como excepción- estaría en contradicción con la noción constitucional de capitalidad. En cambio, sería constitucional y no lesionaría la atribución constitucional de la capitalidad a Madrid que el legislador estableciera la sede de algún órgano constitucional fuera de esta ciudad o que estos órganos pudieran reunirse en otros lugares de España ${ }^{95}$. Es interesante mencionar que en Alemania el Tribunal Constitucional Federal tiene su sede en Karlsruhe, no en Bonn o en Berlín. La capitalidad del art. 5 CE es política, no administrativa por lo que sólo los órganos políticos del Estado deben estar inicialmente en Madrid al encontrarse en ella la capital del Estado. En cambio, los Departamentos Ministeriales así como los distintos órganos reguladores o administraciones independientes pueden tener su sede fuera de la capital, quedando la determinación de su sede en manos del legislador.

Esta interpretación flexible de la noción de capitalidad como sede de las instituciones políticas es la que se encuentra en los Estatutos de Autonomía. Como hemos señalado en otro momento, llama la atención el hecho de que la Constitución no desarrolle más el contenido de la capitalidad de Madrid como sede de las instituciones generales del Estado al mismo tiempo que sí obliga a los Estatutos de Autonomía a contener la «denominación, organización y sede de las instituciones autónomas

94 ALZAGA proponía que la Ley Orgánica que regulase los estados de alarma, excepción y sitio previera el desplazamiento provisional de la capital. Cfr. ALZAGA VILLAAMIL, O., Comentario, cit. pág. 95.

95 El Anteproyecto Constitucional añadía que «podrán establecerse por ley, servicios centrales en otras localidades de España». Para ENTRENA, esta supresión no debe interpretarse como una prohibición de este establecimiento «sino un medio de evitar que se entienda que, por imperativo del precepto constitucional, tales servicios habrán de radicarse necesariamente en Madrid, salvo que una ley establezca lo contrario". Así, esta radicación es una consecuencia obligada de la capitalidad "pero no parece aconsejable establecer la reserva legal para que se apliquen excepciones a esta regla» — la cursiva es nuestra; hago notar que este autor habla, en relación con la ausencia de reserva legal, de servicios centrales, no de órganos constitucionales-. Cfr. ENTRENA CUESTA, R., «Artículo 5», cit. págs. 89-90. Para ARAGÓN, existe una reserva de Ley para regular la sede de las instituciones del Estado pues esto no lo puede hacer el Gobierno ni los propios órganos constitucionales mediante reglamento. Este autor recuerda que el art. 86.1 CE excluye de los Decretos Leyes el ordenamiento de las instituciones básicas del Estado, lo que significa que lo reserva a la ley formal de las Cortes Generales. Esta reserva sería de ley ordinaria, no de ley orgánica, dado el estricto entendimiento del art. 81.1 CE, lo que plantea el problema de la regulación prevista en el art. 6 EAM, que es ley orgánica —loc. cit. págs. 905-906-. 
propias» — art. 147.2.c) CE— ${ }^{96}$. El art. 5 del Estatuto de Autonomía de la Comunidad de Madrid —EAM — identifica la capital de la Comunidad con la sede de las instituciones políticas autonómicas al afirmar que «la capital de la Comunidad, sede de sus instituciones, es la villa de Madrid, pudiendo sus organismos, servicios y dependencias localizarse en otros municipios del territorio de la Comunidad, de acuerdo con criterios de descentralización, desconcentración y coordinación de funciones». El Estatuto de Autonomía de Cataluña, aprobado por Ley Orgánica 6/2006, de 19 de junio, establece: «La capital de Cataluña es la ciudad de Barcelona, que es la sede permanente del Parlamento, de la Presidencia de la Generalitat y del Gobierno, sin perjuicio de que el Parlamento y el Gobierno puedan reunirse en otros lugares de Cataluña, de acuerdo con lo que establecen, respectivamente, el Reglamento del Parlamento y la ley» —art. 10_. El Estatuto de Cataluña de 1979 establecía que en Barcelona debían tener su sede las principales instituciones autonómicas: Parlamento y Gobierno - art. 30.3 y 37.3 - En general existe una disparidad de situaciones en los Estatutos de Autonomía — fijación de la capitalidad, fijación de la sede de las instituciones, remisión al Parlamento autonómico para la fijación de las sedes, etc- En algunas CC.AA. la capitalidad implica la sede del Gobierno y del Parlamento - Madrid, Cataluña, Andalucía, Extremadura, etc-, salvo que exista una regulación específica, como es el caso de Canarias donde la capitalidad está compartida y alterna la sede del Presidente del Gobierno entre Santa Cruz de Tenerife y las Palmas de Gran Canarias, determinándose que el Parlamento tenga su sede permanente en la ciudad de Santa Cruz de Tenerife; o el de Murcia que fija en la capital la sede de las instituciones pero sitúa al Parlamento en Cartagena. La legislación de las CCAA también entiende que la capitalidad implica ser sede de las instituciones generales ${ }^{97}$.

El Estatuto de Autonomía de la Comunidad de Madrid — que tiene el rango de ley orgánica y forma parte del bloque de la constitucionalidad-confirma esta interpretación de la noción de capitalidad del art. $5 \mathrm{CE}^{98}$. Así, este señala que «[1] a villa de Madrid, por su condición de capital del Estado y sede de las instituciones

${ }^{6}$ El Tribunal Constitucional, en la Sentencia 89/1984, de 28 de septiembre, señala que el art. 147.2.c) CE no establece una reserva estatutaria absoluta frente a la Ley de la Comunidad Autónoma que desarrolle la organización de las instituciones autonómicas o que determinara la sede de tales instituciones sino que únicamente supone la absoluta exclusión de norma estatal no estatutaria. De esta forma, el art. 3 del Estatuto de Autonomía de Castilla y León, que establece que «constituidas las Cortes de Castilla y León en la Villa de Tordesillas, aprobarán, en su primera sesión ordinaria, la sede o sedes de sus instituciones de autogobierno, por mayoría de dos tercios» no es contrario al art. 147.2.c) CE porque «aun no fijándose la sede por su nombre, se establece qué órgano habrá de determinarla, cuándo y dónde habrá de hacerlo y con qué mayoría» - F. J. 7. ․․

97 Así, la designación de Santiago de Compostela como capital de Galicia implica ser la sede de las instituciones autonómicas —Ley de Galicia 1/1982, de 24 de junio y 4/2002, de 25 de junio, de Estatuto de Capitalidad de la ciudad de Santiago de Compostela-.

98 VILLAVERDE, no obstante, ha dudado de la constitucionalidad del art. 6 EAM «cuyo exceso competencial parece difícil obviar» —loc. cit. pág. 82-. 
generales, tendrá un régimen especial regulado por Ley votada en Cortes. Dicha Ley determinará las relaciones entre Instituciones estatales, autonómicas y municipales, en el ejercicio de sus respectivas competencias» — art. 6—99. Este precepto del EAM recoge cuál es el contenido jurídico de la capitalidad: ser sede de las instituciones generales del Estado — no precisa cuáles — y facilitar las relaciones entre instituciones estatales, autonómicas y municipales en el ejercicio de las competencias, especialmente — se entiende - aquellas que afecten a la capitalidad. Con anterioridad, el Preámbulo de la Ley Orgánica 6/1982, de 7 de julio, que autorizó la constitución de la provincia de Madrid como Comunidad Autónoma, estableció que Madrid era la «sede de las instituciones democráticas del Estado y del Gobierno de la Nación [....]». Estas disposiciones no suponen un desarrollo legislativo o una concretización del precepto constitucional sino una mera transposición de su contenido. La interpretación flexible de la capitalidad permite establecer la sede de alguna institución del Estado fuera de Madrid sin necesidad de reformar el art. 6 del EAM pues no creemos que el EAM haya congelado la fijación de las sedes.

La Ley 22/2006, de 4 de julio, de Capitalidad y de Régimen Especial de Madrid —LCREM — , también se abona a esta interpretación de la noción de capitalidad, recogiendo que Madrid es «capital del Estado y sede de las instituciones generales» — art. $1.1{ }^{100}$. Esta Ley tampoco define cuáles deben ser las instituciones generales que tengan su sede en Madrid, lo que deja cierto margen al legislador para alguna modificación posterior teniendo en cuenta la interpretación flexible antes defendida. La ausencia de definición de la sede de las instituciones generales en la LCREM puede obedecer a dos razones distintas: la primera sería que es una cuestión pacífica que todos los poderes del Estado y órganos constitucionales tengan su sede en Madrid ya que forma parte del contenido constitucional de la capitalidad; la segunda buscaría evitar un conflicto justo en un momento en el que, con la aprobación de nuevos Estatutos de Autonomía se estaba modificando la distribución competencial entre el Estado y las CCAA, lo que avivó el debate territorial. Cualquier concreción acerca de qué instituciones u órganos constitucionales podían tener su sede fuera de Madrid habría azuzado la discusión sobre el centro y la periferia ${ }^{101}$.

99 Cfr. ENTRENA CUESTA, R., «La capitalidad de la Comunidad de Madrid», en E. ARNALDO ALCUBILlA, (coord.), Comentarios al Estatuto de Autonomía de la Comunidad de Madrid, Comunidad de Madrid, 2003, págs. 91-103.

${ }^{100}$ Cfr. PAREJO ALFONSO, L.; BRAVO RIVERA J., y PRIETO ROMERO, C. (Coord), Estudios sobre la Ley de Capitalidad y de Régimen Especial de Madrid, Bosch, Barcelona, 2006.

101 ALZAGA ya anticipaba que el clima de progresiva regionalización del Estado iba a originar una discusión sobre la organización territorial del Estado por lo que la previsión del art. 5 CE que establecía la capital del Estado dejó esta cuestión al margen del debate —Comentario, cit. págs. 95-96- En la misma dirección, ENTRENA también hace notar que el art. 5 de la Constitución de 1931 contiene un precepto análogo porque al configurar un Estado regional «convenía dejar definitivamente resuelta la cuestión, en evitación de futuras tensiones»——Artículo 5», cit. pág. 89—. 
Posiblemente como hemos señalado en otro momento, éste ha sido uno de los motivos por el que se retrasó tanto la aprobación de una ley de capitalidad. Cualquier regulación especial para Madrid podía haber sido vista con reticencia desde una visión más periférica del Estado — tal vez por esta razón se aprobó antes la Ley 1/2006, de 13 de marzo, de Régimen Especial del Municipio de Barcelona-, sin perjuicio de que este retraso fuera también causado por una cierta reticencia de la Comunidad de Madrid, unida a la falta de iniciativa del Ayuntamiento de la capital. Los primeros veinticinco años de vigencia de nuestra Constitución han sido el momento político para la descentralización territorial y para el afianzamiento de las CC.AA. pero no del Estado Autonómico y, por tanto, no de su capitalidad. El art. 5 CE regula la capital del Estado, expresión orgánica también de la «indisoluble unidad de la Nación española», "patria común e indivisible de todos los españoles». Sin embargo, los años posteriores a la aprobación de nuestra Constitución han sido el momento político para garantizar «el derecho a la autonomía de las nacionalidades y regiones que la integran y la solidaridad entre todas ellas» — art. 2 CE_- Se pensaba que el Estado se encontraba suficientemente fortalecido pues venía de un modelo administrativo centralista y autoritario. Si en estos años no se ha querido fortalecer el Estado, que dispone de una auténtica garantía institucional en nuestra CE, delimitando sus competencias frente a los riesgos que genera la apertura del modelo territorial, en línea con lo mantenido en el Informe del Consejo de Estado de 2006 sobre la reforma constitucional, mucho menos se iba a potenciar su capitalidad. Atribuir más competencias a Madrid iba en el camino opuesto a la descentralización, que buscaba reconocer demandas políticas territoriales. En la actualidad, la regulación de la capitalidad supone un afianzamiento de ésta y afecta — aunque sólo sea simbólicamente- a la organización territorial del Estado.

No obstante, como ya hemos señalado anteriormente, hay que evitar un modelo de capitalidad excesivo que concentre todos los servicios administrativos en Madrid y que centralice la vida económica y cultural en perjuicio de otros territorios. La capitalidad debe ser interpretada en consonancia con la obligación del Estado de «garantizar la realización del principio de solidaridad, velando por el establecimiento de un equilibrio económico adecuado y justo entre las diversas partes del territorio español» — art. 138.1 CE—. En muchos países, la capitalidad no ha impedido el desarrollo de otras ciudades como Frankfurt o Milán. Lo mismo ha ocurrido con la capitalidad de CC.AA., que no ha imposibilitado el desarrollo de otras ciudades —este sería el caso de Málaga en relación con Sevilla o de La Coruña y Vigo en relación con Santiago de Compostela-. Por ello, es razonable que haya organismos públicos que tengan su sede fuera de Madrid de manera que se fomente un mayor equilibrio territorial. Un buen ejemplo de esto ha sido el

\footnotetext{
Para VILLAVERDE, el art. 5 CE solventa «la cuestión jurídico-territorial de asentar en un lugar las instituciones que encarnan una unidad del poder público en un Estado territorialmente descentralizado» —loc. cit. pág. pág. 81 -
} 
establecimiento de la sede de la Escuela Judicial en Barcelona o el traslado de la sede de la Comisión del Mercado de las Telecomunicaciones de Madrid a Barcelona en $2005^{102}$. De esta manera, la capitalidad no debe construirse desde el enfrentamiento entre el centro y la periferia sino desde la colaboración para la consecución de objetivos nacionales, como el de la cohesión y el equilibro territorial. La capitalidad es símbolo de la nación pero no agota ésta, por lo que la regulación de la capitalidad debe permitir mostrar la diversidad de nuestro país.

La Constitución de Alemania recoge de manera explícita una remisión al legislador al señalar que «la regulación [de la capitalidad] se hará por una Ley Federal — art. 22.1—. La Constitución italiana avanza un paso más al señalar que Roma, por ser la capital de la República, tendrá «un régimen propio que se regulará por la legislación del Estado» — art. 114_. En nuestro país, la aprobación de una ley de capitalidad no es una exigencia constitucional. El constituyente tampoco previó la existencia de un régimen especial para Madrid para darle una mayor libertad al legislador ${ }^{103}$. Por tanto, Madrid carece de una garantía institucional en la CE que prevea la existencia de un régimen singular. Sin embargo, posteriormente, el EAM ya citado señala que «[l] a villa de Madrid, por su condición de capital del Estado y sede de las instituciones generales, tendrá un régimen especial regulado por Ley votada en Cortes» — art. 6- . De esta forma, el EAM impone un tratamiento diferenciado del Municipio de Madrid en virtud de la capitalidad, que vincula al legislador estatal. Se establece así una garantía estatutaria de ese régimen estatal singular. El establecimiento de este régimen singular es una posibilidad del legislador que no vulnera el principio de igualdad si se sustenta sobre unos hechos diferenciales de Madrid que justifiquen una ley especial y si el tratamiento es razonable ${ }^{104}$. El Tribunal Constitucional no ha cuestionado la legitimidad de los regímenes especiales establecidos en la D.A. 6. ${ }^{\circ} \mathrm{LBRL}$, una cuestión que fue analizada parcialmente por la STC 214/1989, de 21 de diciembre. Si bien la Constitución no prevé — y no exigeni una regulación de la capitalidad ni unos regímenes municipales especiales, hay que subrayar que el legislador puede más fácilmente eludir la aprobación de una regulación especial para Madrid en tanto que gran población pero es menos libre o se

102 Posteriormente, la Ley 3/2013, de 4 de junio de creación de la Comisión Nacional de los Mercados y la Competencia, que ha supuesto la extinción de la anterior, ha establecido su sede principal en Madrid, aunque la Disposición Adicional tercera del RD 657/2013, de 30 de agosto, que aprueba su Estatuto Orgánico señala que ésta tendrá otra sede en Barcelona donde se situará la Dirección de Telecomunicaciones y del Sector Audiovisual.

103 LUCAS VERDÚ menciona una enmienda de Alianza Popular al Anteproyecto de Constitución, que proponía una ley especial que estableciera un estatuto jurídico para la capital del Estado que sería aprobado por referéndum de sus habitantes pero esta enmienda fue rechazada al entender que esta constitucionalización podría implicar una anticipación no deseable del modelo territorial y era preferible dejar la cuestión a la ley ordinaria. Cfr. LUCAS VERDÚ, P. «Artículo 5.․ La capitalidad», loc. cit. pág. 298. Cfr. también ENTRENA CUESTA, R., «Artículo 5», cit. pág. 89; ALZAGA VILLAAMIL, O., Comentario, cit. pág. 94.

104 Cfr. STC 166/1986, de 19 de diciembre. 
encuentra más condicionado —o al menos tiene una clara apoyatura constitucional— a la hora de aprobar un régimen especial por el hecho capitalino. El Preámbulo - Ide la LCREM señala que «la presente Norma viene a recoger la previsión constitucional de que Madrid es la capital del Estado, reconociendo expresamente esa realidad histórica, y asignándole las funciones propias de dicha condición». Sin embargo, a pesar de que el EAM justifica el régimen especial de Madrid por su condición de capital del Estado, el legislador — como más adelante señalaremos— ha considerado que la gran población de Madrid también demanda un régimen especial. Lógicamente, la regulación de su condición de capital y de gran ciudad tiene un valor distinto: la regulación de la capitalidad tiene un significado constitucional dentro del Estado; la regulación de la gran ciudad tiene un carácter administrativo, vinculado con la gestión pública ${ }^{105}$.

\section{Materias objeto del régimen de capitalidad. La singularidad de Madrid}

El contenido de la capitalidad no sólo hace referencia a la sede de las instituciones generales del Estado sino que, como hemos recogido en otro momento, puede abarcar también otros ámbitos. La regulación de la capitalidad en las leyes de las CC.AA abre la posibilidad de considerar dentro del régimen de capitalidad algunas materias que, por su propia naturaleza, exigen la colaboración entre las distintas Administraciones Públicas. La LCREM ha definido las materias sobre las que incide de manera específica el hecho capitalino y que, por tanto, son el objeto del régimen de capitalidad: la seguridad ciudadana inmediatamente relacionada con la protección de personas y bienes en acontecimientos internacionales o nacionales que se celebren en Madrid en su condición de capital del Estado; la coordinación en la organización y celebración de actos oficiales de carácter estatal; la protección de personas y bienes como consecuencia del ejercicio del derecho de reunión y de manifestación cuando el ámbito de la convocatoria presente dimensión estatal; y el régimen protocolario de la Villa de Madrid y de sus representantes políticos — art. 4-. Estas materias se caracterizan porque están vinculadas a la capital del Estado y en ellas concurren competencias del Estado, la Comunidad de Madrid y el Ayuntamiento de Madrid, que deben desarrollar su actividad administrativa de manera ordenada. Por ello, lo importante del régimen de capitalidad, como hemos señalado en otro momento, no son sólo las materias a las que afecta sino también la regulación de las relaciones interadministrativas en virtud de la capitalidad misma. El concepto de capitalidad obliga a una especial cooperación y colaboración entre todas las Administraciones implicadas. Así, como hemos señalado anteriormente, el EAM establece que la Ley de Capitalidad debe determinar «las relaciones entre las instituciones estatales, autonómicas y muni-

${ }^{105}$ Cfr. los excelentes trabajos de FERNÁNDEZ-MIRANDA, J., Madrid. Área metropolitana, gran ciudad, capital del Estado y de su respectiva Comunidad Autónoma, Colex, Madrid, 2005; id. Evolución histórica del régimen especial de Madrid, Colex, Madrid, 2006. 
cipales, en el ejercicio de sus respectivas competencias» — art. 6-. Por ese motivo, el art. 3 LCREM regula la articulación de las relaciones entre las instituciones estatales, autonómicas y locales en el ámbito territorial de la ciudad de Madrid, «en aquellos aspectos vinculados con la capitalidad», dentro del cual cabe destacar la creación de una Comisión Interadministrativa de Capitalidad como órgano de cooperación entre el Estado, la Comunidad de Madrid y el Ayuntamiento de Madrid que busca facilitar las relaciones entre estas Administraciones que tienen responsabilidades y desarrollan competencias sobre estas materias que afectan a la capitalidad y que favorece la información recíproca sobre las distintas actuaciones, la colaboración en el ejercicio de las mismas, y, en definitiva, la lealtad institucional que debe regir en las relaciones entre Administraciones Públicas en aquellos asuntos que afecten a competencias compartidas o que exijan articular una actividad común.

Hemos mencionado las materias que la LCREM considera que son objeto del régimen de capitalidad. Hay otras materias que no se mencionan en la LCREM pero que también pueden estar vinculadas con la capitalidad, como es la necesidad de un régimen financiero especial para Madrid en virtud de la capitalidad que se concrete en una asignación económica — la compensación capitalina- Por una parte, hay que reconocer que la capitalidad de Madrid presenta indudables ventajas para esta ciudad, especialmente por la concentración tanto de Administraciones Públicas como de empresas privadas, lo que conlleva un actividad económica, unas posibilidades de empleo y un nivel de renta que son inseparables al hecho capitalino. Además, Madrid se beneficia de una oferta cultural — museos, teatros, exposiciones - y de una estructura sanitaria y universitaria, reminiscencia de otras épocas en las que era la capital de un Estado centralizado. En general, existe un conjunto de intangibles, de ventajas indirectas que dimanan de la capitalidad. Esa es la razón por la que cuando ha sido necesario fijar la capitalidad de una Comunidad Autónoma o decidir la ubicación de un organismo de la Unión Europea son varias las ciudades que compiten, conocedoras de los efectos positivos que este hecho conlleva.

Sin embargo, las indudables ventajas que comporta la capitalidad no esconden también la existencia de algunas servidumbres. La capitalidad obliga al Ayuntamiento de Madrid a asumir un conjunto de actividades — celebración de actos oficiales, acontecimientos nacionales e internacionales, manifestaciones, desfiles- a los que hace mención el art. 4 LCREM, que no son las propias de cualquier Entidad Local y que, por tanto, su financiación no está prevista en la Ley de Haciendas Locales. El Ayuntamiento de Madrid tiene que hacer frente con los recursos ordinarios de una Entidad local a obligaciones y gastos en virtud de la capitalidad ${ }^{106}$. Existe una merma de ingresos del Municipio de Madrid derivado de las exenciones de impuestos, tasas y precios públicos —impuesto de bienes inmuebles, impuesto sobre vehículos de

106 En esta dirección, hay que destacar los argumentos que emplea la Exposición de Motivos de la Ley Foral Navarra 16/1997, de 2 de diciembre al establecer un complemento singular a la ciudad de Pamplona en virtud de la capitalidad. 
tracción mecánica — que disfrutan tanto la Administración General del Estado como las legaciones extranjeras — también la Administración de la Comunidad de Madrid, aunque en virtud de la capitalidad autonómica, que no nos corresponde abordar aquí- y que genera un «lucro cesante», al mismo tiempo que se mantiene la obligación de ofrecer servicios públicos en esos ámbitos. La capitalidad conlleva unos gastos que no deben ser costeados sólo por Madrid. La capital es un hecho político del Estado y, por ello, no es razonable que el Ayuntamiento de Madrid soporte unos costes que corresponden a toda la nación.

Por esta razón se ha planteado históricamente tanto en nuestro país como en el derecho comparado la necesidad de una compensación económica por el hecho capitalino, es decir, de una financiación específica del Estado que cubra las necesidades o que compense el hecho de la capitalidad. La Ley de 16 de septiembre de 1932 de la II República concedía a Madrid una subvención por valor de 80 millones de pesetas, pagaderos en los diez años siguientes y destinados exclusivamente a la ejecución de obras y servicios públicos. El preámbulo de la proposición de ley señalaba lo siguiente: «Omitimos, por innecesario, el señalamiento de los grandes desembolsos a que conducen al Ayuntamiento, capital de España, los actos obligados con ocasión de las visitas a España de jefes de Estado extranjeros y de los Congresos nacionales e internacionales de todos órdenes que tienen lugar en Madrid, atendiendo la Corporación municipal debidamente y cual corresponde al decoro de la Nación con los recursos ordinarios de su presupuesto, que tienen por tal concepto una importante merma de los que podría dedicar a servicios puramente locales» ${ }^{107}$. La Ley Reguladora de las Haciendas Locales, aprobada por el Real Decreto Legislativo 2/2004, de 5 de marzo, afirmaba que «[e]l municipio de Madrid tendrá un régimen financiero especial, del que será supletorio lo dispuesto en esta Ley» — art. 160_. El borrador de Anteproyecto de LCREM — preparado por el Ayuntamiento de Madrid-incluía un concreto sistema de financiación en el que se introdujeron una compensación financiera no sólo en virtud de la capitalidad sino por la centralidad y suplencia que soporta la ciudad. Este borrador introdujo incluso algunas modificaciones tributarias que corregían el sistema tributario local, por ejemplo, estableciendo una mayor progresividad en el impuesto de bienes inmuebles en razón de la capacidad económica de los contribuyentes. Finalmente, por falta de acuerdo político, el régimen de financiación especial para Madrid se ha remitido a la reforma de la Ley de Haciendas Locales, que establecerá un nuevo marco de financiación para las entidades locales. Por este motivo, una crítica a la LCREM es el incumplimiento de esta previsión legal de establecer un régimen financiero especial para el Municipio de Madrid. Como es lógico, la financiación especial de Madrid está justificada en tanto que capital del Estado y no

${ }^{107}$ El Decreto 674/1963, de 11 de julio no estableció un régimen especial de financiación para Madrid, a pesar de que el borrador del Proyecto pretendió dotar a Madrid de una subvención especial equivalente a un cinco por mil del Presupuesto General del Estado para compensar la carga de ser capital del Estado. Ya en la democracia el hecho capitalino se cubre económicamente en leyes de las CCAA, como las que regulan la capitalidad de Santiago de Compostela y Pamplona. 
en tanto que gran ciudad, ya que el régimen financiero de las grandes ciudades merece una regulación general para todas ellas y no una norma especial. Por ello, no debe confundirse la suficiencia económica de las haciendas locales, que afecta a Madrid en tanto que gran ciudad, con la necesidad de un régimen financiero especial para Madrid en virtud de la capitalidad.

La LCREM, después de mencionar unas materias que son objeto del régimen de capitalidad, incluye también una cláusula abierta que alcanza a «cualquier otra materia que pudiera afectar relevantemente a las tres Administraciones, a juicio de las mismas, como consecuencia de la capitalidad de Madrid»—art. 4.e)—. El hecho de que la ley no deje cerradas las materias a las que puede afectar el régimen de capitalidad, permitiendo su ampliación por la Comisión Interadministrativa de la Capitalidad, no supone un menoscabo a la autonomía de las tres Administraciones, tampoco de la autonomía local del Ayuntamiento de Madrid, porque es necesaria la voluntad unánime de las tres Administraciones para que la Comisión, a partir de las necesidades que surjan, pueda decidir ampliar la actividad administrativa que merezca un ejercicio conjunto. Por tanto, el Ayuntamiento de Madrid conserva en plenitud su autonomía municipal garantizada constitucionalmente — art. 140 CE—. Si bien la normativa de capitalidad ha sido utilizada en el derecho comparado para debilitar la autonomía local, esto no se produce en la LCREM, que tiene como vocación un fortalecimiento del Ayuntamiento de Madrid. Incluso si la capitalidad no implica una mayor atribución competencial para el Ayuntamiento, sí permite una mayor participación a través de la Comisión Interadministrativa en algunas competencias de otras Administraciones Públicas.

La LCREM trata de restringir el régimen de capitalidad a las materias vinculadas claramente a ésta. La cláusula abierta incluida en el art. 4.e) LCREM no permite introducir dentro del régimen de capitalidad cualquier otra materia que voluntariamente las tres Administraciones quieran incluir dentro del régimen de relaciones interadministrativas sino únicamente a «cualquier otra materia que pudiera afectar relevantemente a las tres Administraciones, a juicio de las mismas, como consecuencia de la capitalidad de Madrid». Por tanto, para incluirse dentro de este régimen tiene que ser una materia que le afecte a estas Administraciones a consecuencia de la capitalidad y tiene que ser aceptado de manera unánime por las tres Administraciones. De hecho, toda la regulación del régimen de capitalidad está organizada para respetar las competencias de las tres Administraciones Públicas. Así, la Comisión Interadministrativa de Capitalidad se configura como un órgano de cooperación y no de coordinación y está formado por igual número de miembros de las tres Administraciones - art. 5 LCREM-.

De hecho, se puede afirmar que la limitación del régimen de capitalidad a unas materias concretas no trata principalmente de garantizar las competencias del Ayuntamiento de Madrid sino sobre todo las de otras Administraciones Públicas, especialmente las de la Comunidad de Madrid. El EAM asume la existencia de un régimen especial en virtud de la capitalidad, con un contenido concreto — que es la noción 
constitucional—que se explicita en el art. 6. En cambio, este Estatuto no admite un régimen especial que modifique la distribución constitucional de competencias y que afecte a cualquier materia sobre la que tenga interés el Ayuntamiento de Madrid. El EAM limitaba las materias que deben ser objeto de relaciones interadministrativas en virtud de la capitalidad. Por tanto, la LCREM cumple plenamente el mandato estatutario en los mismos términos en que se ha aprobado. La inclusión dentro de este régimen de capitalidad de cualquier otra materia que excediera de la capitalidad vulneraría el mandato estatutario.

La LCREM contiene, a nuestro juicio acertadamente, una limitación de las materias que caen dentro del régimen de capitalidad. No obstante, la regulación de estas materias y, por tanto, de la capitalidad es bastante pobre. Posiblemente se perdió la oportunidad de desarrollar el régimen de capitalidad en aquellos ámbitos que forman parte del contenido constitucional. La LCREM enumera las materias sobre las que incide el hecho capitalino pero no las ha desarrollado. Por tanto, no hay un desarrollo político del precepto constitucional: no se establece nada acerca de la sede de las instituciones generales — sobre la posibilidad de reuniones extraordinarias fuera de Madrid o de descentralizar dependencias administrativas-, no se concreta una compensación capitalina, no se regula nada del protocolo y honores de la ciudad y de los representantes de Madrid, algo se añade — más bien poco_ - en materia de seguridad ciudadana relacionada con acontecimientos nacionales y manifestaciones de ámbito estatal y en la participación en la organización de actos oficiales estatales. Es, por tanto, una ley que se llama de capitalidad pero que no desarrolla la capitalidad. Realmente la Ley 22/2006, de 4 de julio es más una Ley de Régimen Especial de Madrid por su carácter de gran ciudad que una Ley de Capitalidad.

La auténtica singularidad de Madrid — la única que la hace realmente singulares el hecho de la capitalidad. El carácter de gran ciudad no es una singularidad de Madrid sino que se da en otras ciudades con las que Madrid comparte la problemática específica que presentan las grandes urbes. No existe en este caso un supuesto de hecho singular que justifique un régimen especial para Madrid sino que inicialmente también podría remitirse a la normativa general de régimen local que regula las grandes ciudades, como la Ley 57/2003, de 16 de diciembre, de medidas para la modernización del gobierno local. En todo caso, la necesidad de delimitar las materias que caen dentro del régimen de capitalidad es compatible con asumir que el fenómeno de la capitalidad y de la gran ciudad se encuentran entretejidos. Así, la segunda razón que a juicio de la LCREM justifica un régimen especial para Madrid es su condición de gran ciudad. Para el legislador la singularidad institucional — la capitalidad — está vinculada a la singularidad social — la gran población-: «[e]stas singularidades, tanto institucionales como sociales, se encuentran estrechamente entrelazadas: la realidad de Madrid como gran ciudad es indisociable de su condición de capital del Estado» - Preámbulo I_. La capitalidad del Estado le da una mayor dimensión a su carácter de gran ciudad. Madrid sería una gran ciudad aunque no fuera capital del Estado pero el hecho de serlo ha hecho que lo sea en términos que no admiten comparación. 
Madrid no es sólo una gran ciudad sino que es la ciudad más poblada de España, con más de tres millones y medio de habitantes, teniendo en cuenta la inmigración irregular, y de cinco millones de personas si consideramos la población que trabaja y se mueve diariamente por Madrid. Madrid no es sólo la ciudad más poblada de España — con mucha diferencia en relación con las demás_-; es también la segunda capital de la Unión Europea sólo superada por Berlín. Si bien nuestro país tiene otras grandes ciudades, ninguna alcanza una población comparable a la de la ciudad de Madrid. Esta supera con creces la población de muchas Comunidades Autónomas, lo que puede llegar a justificar una arquitectura institucional y organizativa específica más parecida a la de las Comunidades Autónomas que a la de los Ayuntamientos, establecida a través de un régimen municipal especial. Por ello, la LCREM lleva a cabo un tratamiento integrado porque no siempre se puede separar la condición de gran ciudad del hecho de la capitalidad. La capitalidad ayuda a justificar que se apruebe la ley que no es en el fondo de capitalidad sino que establece para Madrid un régimen municipal especial.

Madrid también presenta una tercera dimensión que es la de ser centro de una extensa área metropolitana. Si nuestra Constitución no menciona las grandes ciudades, tampoco menciona las «ciudades metropolitanas», a diferencia de la Constitución italiana que sí lo hace en el art. 114. Sin embargo, quien atiende los problemas de esta área metropolitana no es la ciudad de Madrid sino la Comunidad Autónoma, Administración territorial que alberga dentro si este área metropolitana. La Comunidad de Madrid ha cubierto las necesidades de coordinación de los municipios limítrofes con importantes vínculos económicos y sociales. Poco sentido tiene crear entes metropolitanos por la identidad que existe entre el fenómeno metropolitano de Madrid y la Comunidad de Madrid. Por tanto, la Comunidad de Madrid no sólo ha asumido las funciones de la antigua Diputación Provincial sino también las de otras entidades locales no necesarias como los entes metropolitanos. Las potestades administrativas que puede ejercer el ente metropolitano ya las desarrolla la Comunidad de Madrid, evitando que el Ayuntamiento extienda sus competencias fuera de su ámbito territorial.

De hecho, muchos de los problemas que tiene Madrid en todas sus dimensiones — capital, gran ciudad, fenómeno metropolitano_ — no sólo son resueltos por la Comunidad de Madrid sino que es lo que justifica su nacimiento. No tiene sentido atribuir a la ciudad de Madrid más potestades y competencias si quien las desarrolla es una Administración Autonómica cercana con un amplísimo nivel de autogobierno. Si bien no se puede decir que la Comunidad de Madrid haya limitado la autonomía local del Ayuntamiento de Madrid, sí se puede afirmar que de no existir esta Comunidad Autónoma uniprovincial la dinámica institucional probablemente hubiera sido distinta. Se podía haber ido al modelo característico de los Estados Federales que configuran la capital como un Distrito Federal separado de los Estados — Washington D. C. o hasta 2016 el caso Méjico D. F._- que suprime la autonomía local y que evita la posición preeminente en el conjunto de la Federación del Estado miembro en cuyo territorio se localice 
la ciudad elegida; o a un modelo de ciudad-estado como el de Berlín — que identifica al Ayuntamiento con uno de los Estados-, Ciudad de Méjico — que es una de las treinta y dos entidades federativas que conforman esta República- o Viena — considerada un Estado por el art. 108 de la Constitución de Austria, desempeñando el Ayuntamiento las funciones de Dieta Regional y el Alcalde las de Gobernador del Estado-; o a un modelo de Comunidad Autónoma pluriprovincial — que atribuya al Municipio de Madrid más competencias, como ha ocurrido con Barcelona dentro de Cataluña- Así, el nacimiento de la Comunidad de Madrid como Comunidad Autónoma uniprovincial ha sido un factor que cuestionó la necesidad de aprobar una ley de capitalidad y de régimen especial de Madrid ya que los problemas y las exigencias municipales se resolvían a través del nacimiento de esta Comunidad Autónoma. En esta dirección, la configuración de un fuerte estatuto de capitalidad y de gran ciudad para Madrid podía significar un menoscabo de las competencias autonómicas. Existe un conjunto de dificultades objetivas en las relaciones entre el Ayuntamiento de Madrid y la Comunidad de Madrid — que coinciden en ámbito territorial— que se han manifestado a lo largo del tiempo en diversos problemas institucionales entre ambas Administraciones Territoriales. Por tanto, la existencia de una Comunidad Autónoma de Madrid ha influido no sólo en el retraso de la aprobación de un régimen especial de Madrid sino también en su carácter menos ambicioso.

Por último, la capitalidad, reconocida en el art. 5 CE, es la máxima expresión de la unidad de la nación española — art. 2 CE—. Como señala Aragón, «las ciudades-capital aparecen en Europa occidental en la baja Edad Media como instrumento de afirmación de las unidades políticas territoriales frente al Imperio y, sobre todo, frente a Roma, caput mundi» ${ }^{108}$. Si las competencias exclusivas tienen como finalidad preservar la actividad del Estado frente a las CC.AA., la regulación de la capitalidad y, por tanto, la aprobación de un régimen especial vinculado a la misma es una consecuencia organizativa de la indisolubilidad de la nación y, por tanto, es competencia exclusiva del Estado. Teniendo claro que el Estado es competente para legislar sobre la capitalidad, no está tan claro cuál es el título habilitante ya que no se encuentra explicitada en el art. 149 CE la competencia exclusiva a favor del legislador estatal en relación con la capitalidad. Al legislador no le ha parecido suficiente a efectos de la habilitación constitucional de la competencia exclusiva del Estado los arts. 2 y 5 CE. Por ello, la Disposición Final Primera LCREM dedicada a la habilitación competencial justifica la del régimen de capitalidad — arts. 3 al 6 y la disposición adicional primera- en virtud del art. 149.1.18. ${ }^{a} \mathrm{CE}$, que atribuye al Estado la competencia exclusiva sobre el «régimen jurídico de las Administraciones públicas y del régimen estatutario de sus funcionarios que, en todo caso, garantizarán a los administrados un tratamiento común ante ellas [...]». El legislador ha entendido así que la regulación de la capitalidad forma parte del régimen local y su título habilitante se encuentra en el art. 149.1.18. ${ }^{\mathrm{a}} \mathrm{CE}$.

${ }^{108}$ Cfr. ARAGÓN REYES, M., loc. cit. pág. 902. 


\section{Title}

The flag and the capital

\section{Summary:}

I. The symbols. II. The flag. 1. The flag as a symbol of the State and as an element of integration of citizens in the community and the constitutionalization of regional flags 2. The conflicts over the use of the flags: the flags war. a) The obligation to use the Spanish flag in public buildings and official acts and their non-compliance. b) The criminal protection of the flag and its questioning as a limit to freedom of expression. c) The prohibition of the display of partisan flags in public buildings and the partisan use of the Spanish flag. d) Conflicts over the use of the flags of the Autonomous Communities. III. The capital. 1. The constitutional concept of the capital: the seat of the general institutions of the State. 2. Competences regulated by the Capital Law. The singularity of Madrid.

\section{Resumen:}

En este artículo se abordan dos elementos que han estado presentes en la conformación de nuestra identidad nacional: la bandera y la capitalidad. En primer lugar, se analiza el papel de los símbolos en la relación entre socialización e individualidad, entre lo racional y lo emocional, lo mítico o lo intuitivo, algo esencial en los Estados democráticos para alejarnos de los totalitarismos, teniendo en cuenta la capacidad de los nacionalismos, los fascismos y los populismos de manipular en ese espacio. En segundo lugar se estudia la bandera como símbolo del Estado tanto desde una perspectiva de derecho comparado y de historia constitucional como teniendo en cuenta su actual regulación constitucional. Igualmente se analiza la exhibición de la bandera como elemento de integración voluntaria y consciente de los ciudadanos en la comunidad y como defensa de la unidad de España y de reivindicación de la CE y de las libertades de todos, también de los ciudadanos catalanes, ante el problema de libertad que ha supuesto la declaración unilateral de independencia, como ha ocurrido recientemente con la presencia masiva de la bandera española en los balcones. También se estudia la constitucionalización de las banderas autonómicas y el establecimiento de una obligación de utilización conjunta de éstas junto a la bandera de España, símbolo de una España constitucional y democrática, que reconoce un alto nivel de autogobierno a sus nacionalidades y regiones. Asimismo se abordan los conflictos por el uso de las banderas - la llamada guerra de las banderas - , analizándose las Sentencias más recientes, que ponen de manifestó la crisis en el sentido de pertenencia a España derivada de nuestra diversidad territorial. Así, se analiza el incumplimiento de la obligación de utilizar la bandera de España en edificios públicos y actos oficiales. También se aborda la bandera como bien jurídico merecedor de protección penal y el cuestionamiento del delito de ultrajes a la bandera, un límite a la libertad de expresión querido por el legislador, lo que pros- 
cribe una conducta expresiva como la quema de la bandera. Igualmente se analiza la doctrina de la JEC sobre la prohibición de la exhibición de banderas esteladas en edificios públicos en aplicación del principio de neutralidad política de la Administración Pública, sin perjuicio de su uso legítimo por entidades privadas en virtud de la libertad de expresión, así como la prohibición de la utilización de la bandera de España como símbolo oficial de un partido político, que traslada a la sociedad la idea de que la bandera es patrimonio de una parte de la población. En tercer lugar, se analiza el concepto constitucional de capitalidad. La capitalidad no es en puridad un símbolo aunque tiene un importante componente simbólico. Atribuir a una ciudad la capitalidad significa convertirla en cabeza política de un territorio y concederle una posición central dentro del Estado. Igualmente la capitalidad hace referencia a un lugar fijo donde se ejerce la soberanía y, por tanto, sede de los órganos de poder del Estado. Este estudio aboga por una interpretación flexible que no vacíe de contenido constitucional la noción de capitalidad y que al mismo tiempo permita un margen de maniobra al legislador en el marco de un Estado fuertemente descentralizado. Así, los órganos de poder del Estado y los órganos constitucionales deben tener su sede en Madrid, si bien la existencia de alguna excepción no vulneraría el precepto constitucional. Finalmente el trabajo aborda cuáles son las materias objeto del régimen de capitalidad y las otras singularidades de Madrid.

\begin{abstract}
:
This article deals with two elements that have been present in the shaping of our national identity: the flag and the capital. Firstly, it analyzes the role of symbols in the relationship between socialization and individuality, between the rational and the emotional, the myth or the intuitive, something essential in democratic states to steer ourselves away from totalitarianism, taking into account the capacity of the nationalisms, fascism and populisms to manipulate in that space. Secondly, it studies the flag as a symbol of the State, both from the point of view of Comparative Law and constitutional history, as well as considering its current constitutional regulation. Thus, the display of the flag is also analyzed as an element of voluntary and conscious integration of citizens in the community, and as a defense of Spain's unity and the Constitution and the freedoms of all citizens, including Catalan citizens, in response to the problem of freedom that the unilateral declaration of independence of Catalonia has implied, as we have seen recently with a massive presence of the Spanish flag on the balconies. The article also studies the constitutionalization of the regional flags and the establishment of an obligation of the joint use of these together with the flag of Spain, which is a symbol of a constitutional and democratic Spain, that recognizes a high level of self-government towards its nationalities and regions. Furthermore, it also studies the conflicts that arise from the use of flags — the so-called «war of the flags»—, analyzing
\end{abstract}


the most recent cases, which highlights the crisis in the sense of belonging to Spain derived from our territorial diversity. In the same manner, it also examines the breach of the obligation to use the Spanish flag in public buildings and official acts. Moreover the flag is also analysed as a constitutional value worthy of criminal protection; this also study the crime for flag desecration as a limit on the freedom of speech, which outlaws the burning of the flag as expressive conduct. It also discusses the JEC doctrine on the prohibition of the display of the «estelladas» in public buildings as a result of the application of the principle of political neutrality of the Public Administration, even though they can be used legitimately under the freedom of expression by private entities. Furthermore, the article also examines the prohibition of the use of the flag of Spain as an official symbol of a political party, which consequently conveys to society the idea that the flag belongs to a part of the population rather than to the entire country. Thirdly, the study analyzes the constitutional concept of the capital. The capital is not strictly speaking a symbol, but it has an important symbolic meaning. To attribute to a city the capitality means to turn it into the political head of a territory and to grant it a central position within the State. Likewise, the capital status refers to a fixed place where sovereignty is exercised and, thus, is the seat of the general institutions of the State. This study pleads for a flexible interpretation that does not empty the constitutional content of the notion of capital and at the same time allows a margin of freedom to the legislator in the framework of a strongly decentralized State. Therefore, the organs of state power and constitutional bodies must have their headquarters in Madrid, although the existence of any exception would not violate the constitutional provision. Finally, the paper addresses which the competences regulated by the Capital Law are as well as other singularities of Madrid.

\section{Palabras clave:}

Bandera, capitalidad, delito de ultrajes a la bandera, símbolos del Estado

\section{Key words:}

Flag, capital, crime for flag desecration, State's symbols. 